Article

\title{
Subjective Product Evaluation System Based on Kansei Engineering and Analytic Hierarchy Process
}

\author{
Yaxue Zuo and Zhenya Wang * \\ School of Mechanical Engineering, Shandong University, Jinan 250061, China; zuoyaxue@mail.sdu.edu.cn \\ * Correspondence: wangzhenya@sdu.edu.cn
}

Received: 14 July 2020; Accepted: 6 August 2020; Published: 11 August 2020

\begin{abstract}
Product evaluation is very important for product improvement and development, and subjective product evaluation determines customer's evaluation of products to some extent, so the purpose of this study is to establish a reasonable subjective product evaluation system. In this study, we comprehensively determine the evaluation indexes based on Kansei engineering (KE), establish an overall product evaluation system by using analytic hierarchy process (AHP), and establish the subjective product evaluation system by classifying the evaluation indexes in the overall product evaluation system into "objective evaluation index" and "subjective evaluation index", removing the objective evaluation indexes, and retaining the subjective evaluation indexes. Additionally, we select some modern chairs as experimental samples to verify the reliability and validity of this subjective product evaluation system by means of questionnaires. The experimental results show that, in this subjective product evaluation system, the subjective evaluation of the product is positively correlated with the "favorite" level of the product in comprehensive evaluation, and negatively correlated with the "least favorite" level of the product in comprehensive evaluation, indicating that this subjective product evaluation system realizes a symmetry between subjective product evaluation and comprehensive product evaluation. Therefore, it can be concluded that this subjective product evaluation system based on KE and AHP proposed in this study has reliability and validity, and can be used for product evaluation to judge the popularity of products and enhance the competitiveness of products.
\end{abstract}

Keywords: analytic hierarchy process; Kansei engineering; product evaluation; subjective product evaluation system

\section{Introduction}

The trend of product development has already changed towards the consumer-oriented; namely, the consumer's feeling and needs are recognized as invaluable in product development for manufacturers [1,2]. The "physical" performance of the product is no longer the only focus, and the "spiritual" performance of the product is getting more and more attention [3]. The products on the market must not only meet the basic physical and physiological needs of customers, but also satisfy the spiritual and emotional needs of customers [4-6].

Kansei engineering (KE), as a representative method of emotional design, has been widely used in the design field since its introduction [7]. Different from conventional emotional design methods, KE is a consumer-oriented ergonomics-based product design support technology that transforms vague emotional needs and images into design elements of products [3,8]. Up to now, there have been a lot of researches related to KE. Chang and Chen established a KE model that can integrate the interrelations of constituent elements to determine consumer emotional perception and preferences in a case regarding steering wheel design [9]; Cucuk et al. conducted research to determine the elements that must be considered in desk and chair design for elementary school, and KE is used in this research to capture 
the image of a design emotionally [10]; Bruno and Luis investigated user's emotional perception of disposable razors with different features by KE [11]; Guo et al. proposed an optimization design method of website interface based on KE theory, and applied this method to a job-hunting website homepage [12]; Akihito et al. used KE knowledge to identify and remedy difficulties related to user interface development in the study of motion-based Kinect game system [13]; Rui et al. took the entire journey of passengers on a bus as an example to apply KE to the product-service system to improve customer experience [14]; Yukihiro et al. promoted several KE investigation to the civil engineering constructions in their research project, to show the necessity of applying KE to public constructions design [15].

At the same time, multi-criteria decision-making (MCDM), as a complex decision-making (DM) tool involving both quantitative and qualitative factors [16], can help designers create products taking into account the customer's psychological needs in relation to the appearance of products [17]. Analytic hierarchy process (AHP) is one of the MCDM methods, which has been used in many fields since its introduction [18-20]. Javalgi et al. used AHP in different contexts to support decision-making in relation to consumers' bank selections [21]; Ball and Srinivasan presented a formal judgmental model of the house selection process using AHP [22]; many scholars have also applied AHP in the health sector, to determine which tests should be performed given certain symptoms [23], and evaluated different medical treatment strategies [24,25]; Sarkis and Talluri showed that AHP can be used to evaluate and select e-commerce software and communication systems for the supply chain [26]; Levary applied AHP for ranking and evaluating potential suppliers in the supplier selection process [27]; Salgado, Salomon, and Mello presented the application of AHP to prioritize activities of new product development for manufacturing companies of electronic products [28]; Razi and Karatas used AHP to generate ranking and assign weights to different incident types in the context of an incident based-boat allocation model, used to decide the location of search and rescue boats [29].

The purpose of this study is to propose a subjective product evaluation system based on KE and AHP, with KE as the theoretical basis and AHP as the system establishment method. Of course, there have been some successful studies combining KE and AHP already. Petiot and Yannou presented a general approach to assess product semantics, which involves several classical methods in marketing and decision-making theory, such as KE, AHP and so on, and applied it to the design of table glasses [30]; Zhu introduced KE and AHP into the research of home service robot design, and then proposed a more scientific design scheme for the shape design of home service robot, which is more in line with the user's perceptual needs [31]; Zhou et al. proposed a collaborative filtering recommendation approach based on KE and AHP for clothing personalized recommendations [32]; Yuan et al. proposed a multi-image evaluation method for human-machine interface based on KE and AHP, which provides an effective evaluation method for human-machine interface design, and helps to meet user's perceptual needs for human-machine interface [33]; Hadiana implemented KE and AHP to select a mobile learning system with a suitable interface for students in the research [34]; Syaifoelida et al. integrated KE and AHP in product development, and used the design of a car center stack as a case study to apply this idea [35]; Huda and Hadiana built a decision support system for choosing helpdesk, where KE is used to translate feelings into product design, and AHP is used for determining decisions [36].

However, by summarizing the above studies, we can find the existing studies combining KE and AHP have the following drawbacks: (1) most of these studies are aimed at a specific research object, which leads to the research models or results in these studies only applicable to the research objects in these studies, that is, the application scope of these studies is narrow; (2) these studies mainly focus on the concrete elements such as the shape, material, color, and interactive mode of the research objects, but do not pay attention to the abstract elements, which leads to the incomprehensive research scope of these studies; (3) these studies are all based on KE and AHP, both of which have strong subjectivity, but these studies do not take into account the unsuitability of objective elements in receiving perceptual evaluation, which leads to errors in research results; (4) all these studies apply KE in the traditional way, that is, it is necessary to collect a large number of perceptual phrases, and then 
select the perceptual phrases suitable for the research objects for analysis, which has a large workload and limits the extended application of the research results. In view of the drawbacks of the above studies, this study has made corresponding improvements: (1) based on the whole product field, this study explores various evaluation factors of the product under the four attributes of the product to establish the evaluation systems of this study, which makes the application scope of this study wider; (2) under the four attributes of products, this study summarizes the evaluation indexes of products, considering not only the concrete product elements such as product shape, color, and material, but also the abstract product elements, such as cultural connotation and social influence, which makes this study more comprehensive and reasonable; (3) this study comprehensively considers the factors influencing product evaluation based on KE, establishes an overall product evaluation system by using AHP, and then obtains the subjective product evaluation system by eliminating the objective evaluation indexes in the overall product evaluation system and retaining the subjective evaluation indexes, which effectively reduces the research errors and makes the research more reasonable; (4) this study simplifies the traditional KE, instead of searching for suitable perceptual phrases from a large number of perceptual words, it sets the perceptual phrases corresponding to all subjective evaluation indexes as "weak-strong", which makes the application scope of the research result wider.

\section{Methods}

\subsection{Research Framework}

This study consists of three parts, as shown in Figure 1. In part 1, KE and AHP are used to construct an overall product evaluation framework, that is, a hierarchy structure model. There are four levels in this framework, including the overall evaluation level, attribute level, aspect level, and evaluation index level. Then, the AHP is used to calculate the relative weight of each element at each level to obtain the overall product evaluation system. In part 2, the overall product evaluation system is divided into a subjective product evaluation system, and an objective product evaluation system. In part 3, 10 representative chair products are selected as experimental samples, and then appropriate subjects are selected to participate in the experiment to verify the validity and rationality of this subjective product evaluation system.

\subsection{Kansei Engineering}

KE is founded by Professor Mitsuo Nagamachi at Hiroshima University in the 1970s [1,37]. It aims at the implementation of the customer's feeling and demands into product function and design. Kansei is a Japanese word, which means the customer's psychological feeling, as well as embracing physiological issues. KE is defined as "translating the customer's kansei into the product design domain" $[1,2,38]$. In the field of industrial design, it expresses people's perceptual image of "things" quantitatively and semi-quantitatively, and associates it with product design characteristics, so as to realize the perceptual feeling of "people" (including consumers, designers, etc.) in product design and design products that meet the sensory expectations of "people" [3]. Usually, we use the semantic differentials (SD), developed by Osgood and his colleagues [39], as a main technique to grasp the consumer's kansei. SD is a basic research method, which reflects the user's perception on the Likert scale (usually the 5-point, 7-point, or 9-point scale) through the semantics of the research object (including the shape of the product, the color of the product, etc.), and then analyzes the laws by statistical methods [40]. The main purpose of this study is to establish a subjective product evaluation system that is as universal as possible, so our research object transitions from the whole of each product to the various influencing factors of each product (the influencing factors of each product are the same), and the evaluation of these influencing factors needs to be quantified uniformly. Therefore, on the basis of the theory of KE, we set the evaluation adjectives of these influencing factors as "weak-strong". The scale used in this study is the 5-point scale, as shown in Figure 2. 


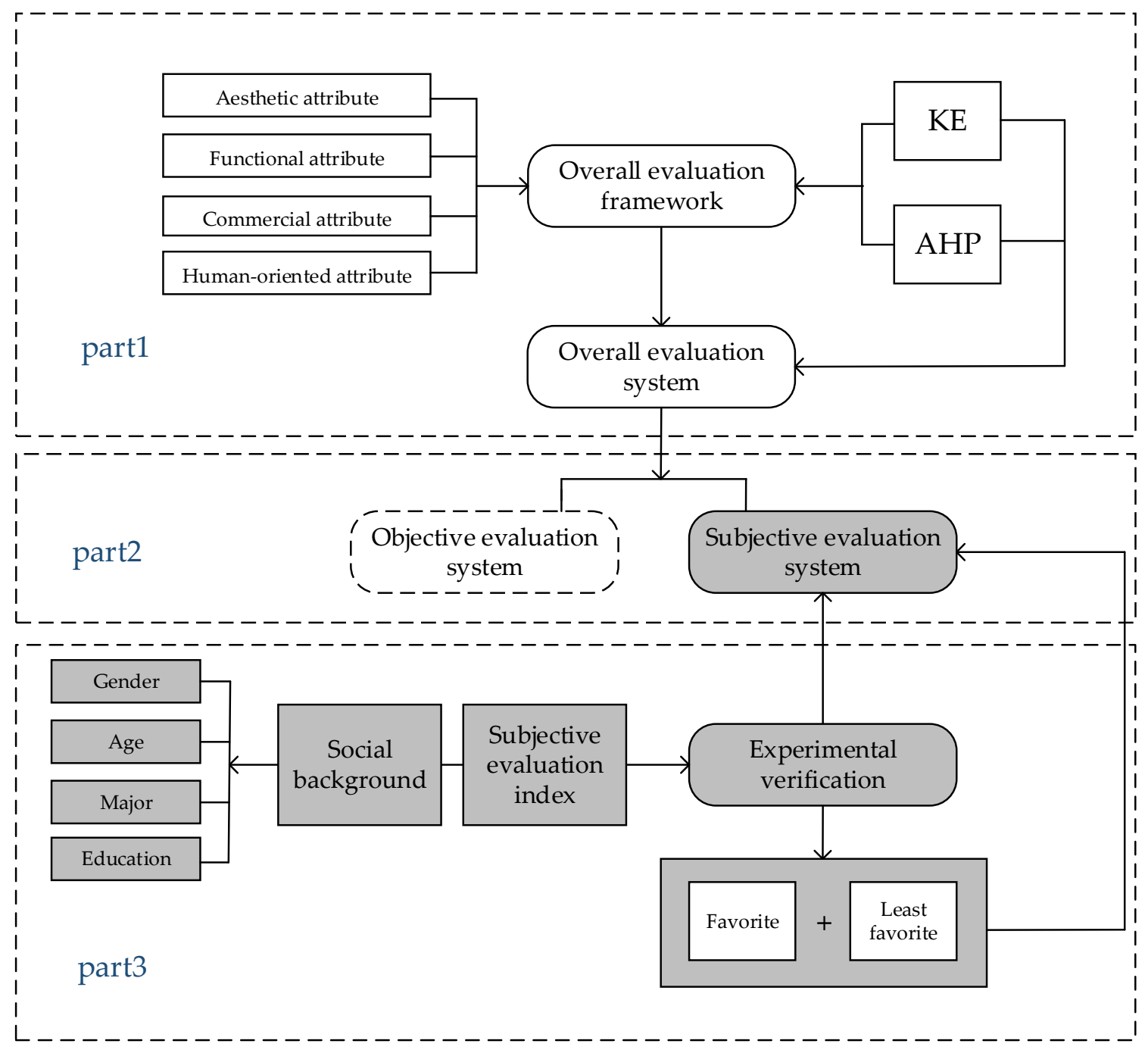

Figure 1. Research framework.

What do you think of the factor $\mathbf{A}_{i}$ of this product?

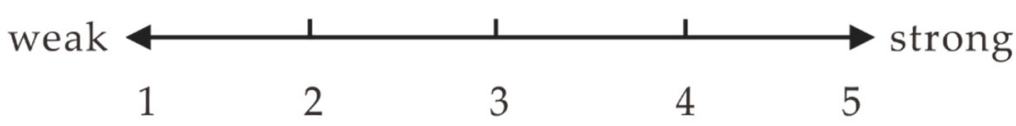

Figure 2. The 5-point scale.

\subsection{Analytic Hierarchy Process}

AHP, developed by Thomas L. Saaty in 1971-1975 [41], is a MCDM method helping decision-maker facing a complex problem with multiple conflicting and subjective criteria $[16,20,42,43]$. The core concept of AHP is decomposing a complex problem into a hierarchy structure (Figure 3), and assessing the relative importance of these criteria/indexes by pairwise comparison [44]. When setting up the AHP hierarchy with a large number of elements, the decision maker should attempt to arrange these elements in cluster so they do not differ in extreme ways [42,45,46]. In this study, we take the "evaluation indexes" in evaluation system as the indexes of the hierarchy structure, and the "evaluation indexes" are also the influencing factors in KE. 


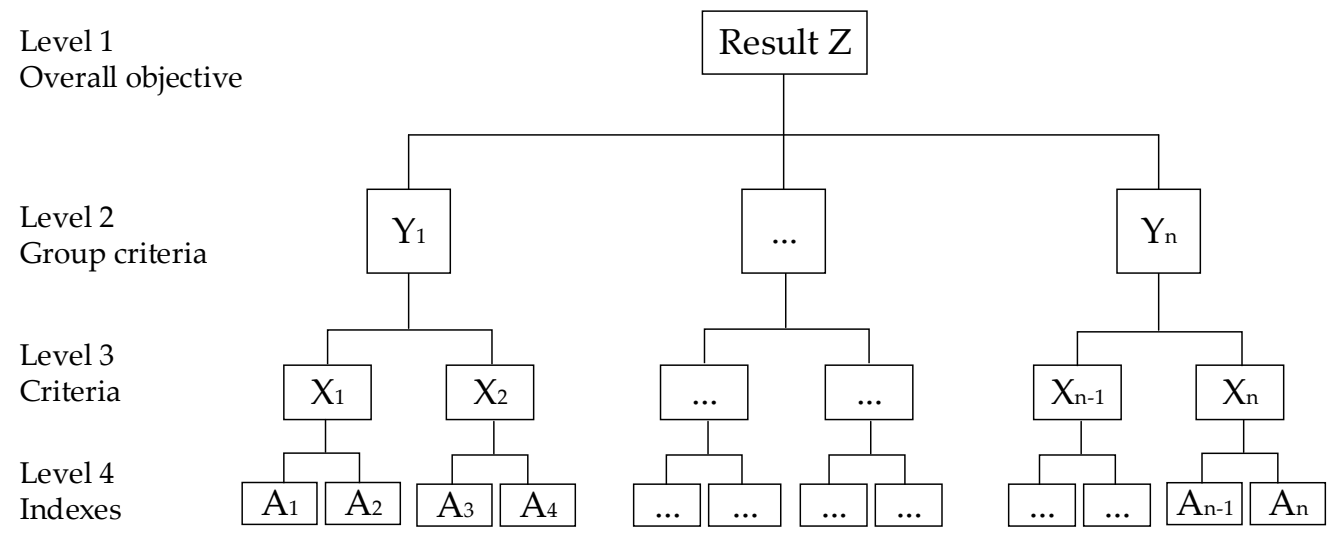

Figure 3. The hierarchy structure.

In AHP, after the hierarchy is constructed, we need to construct judgment matrices by pairwise comparing the importance of elements of the same level in the hierarchy based on the 1-9 fundamental scale (Table 1).

Table 1. The 1-9 fundamental scale [43].

\begin{tabular}{cc}
\hline Intensity of Importance & Definition \\
\hline 1 & Equal importance \\
3 & Weak importance of one over another \\
5 & Essential or strong importance \\
7 & Demonstrated importance \\
9 & Absolute importance \\
$2,4,6,8$ & Intermediate values between the two adjacent judgments \\
\hline
\end{tabular}

For example, $A$ is an $\mathrm{n} \cdot \mathrm{n}$ pairwise comparison matrix (1), where $a_{i j}$ is the comparison between element $i$ and $j$, and $a_{j i}=1 / a_{i j}$.

$$
A=\left[\begin{array}{cccc}
1 & a_{12} & \cdots & a_{1 n} \\
a_{21} & \cdots & a_{i j} & \cdots \\
\cdots & a_{j i}=1 / a_{i j} & \cdots & \ldots \\
a_{n 1} & \cdots & \cdots & 1
\end{array}\right], i=1,2,3, \ldots n
$$

We normalize $A$ twice to obtain its eigenvector $W$.

$$
\begin{gathered}
w_{i}=\frac{\prod_{j=1}^{n} \sqrt[n]{a_{i j}}}{\sum_{i=1}^{n} \prod_{j=1}^{n} \sqrt[n]{a_{i j}}}, \\
W=\left(w_{1}, w_{2}, \ldots, w_{n}\right)^{T} .
\end{gathered}
$$

Then we need to calculate the maximum eigenvalue $\lambda_{\max }$ of $A$.

$$
\begin{gathered}
A W=\lambda_{\max } W, \\
\lambda_{\max }=\frac{1}{n} \sum_{i=1}^{n} \frac{(A W)_{i}}{w_{i}} .
\end{gathered}
$$

In $\mathrm{AHP}$, as priorities make sense only if derived from consistent or near consistent matrices, the consistency check must be applied. Only if the consistency ratio $(C R)$ is less than 0.1 , then the 
matrix can be considered as having an acceptable consistency, and reasonable, otherwise the matrix needs to be adjusted to acquire an acceptable consistency.

$$
\begin{gathered}
C R=\frac{C I}{R I}, \\
C I=\frac{\lambda_{\text {max }}-n}{n-1},
\end{gathered}
$$

$C I$ is the consistency index, $R I$ is the random index, and the value of $R I$ is shown in Table 2.

Table 2. Random index (RI) values [43].

\begin{tabular}{ccccccccccc}
\hline $\boldsymbol{n}$ & $\mathbf{1}$ & $\mathbf{2}$ & $\mathbf{3}$ & $\mathbf{4}$ & $\mathbf{5}$ & $\mathbf{6}$ & $\mathbf{7}$ & $\mathbf{8}$ & $\mathbf{9}$ & $\mathbf{1 0}$ \\
\hline$R I$ & 0 & 0 & 0.52 & 0.89 & 1.12 & 1.24 & 1.36 & 1.41 & 1.46 & 1.49 \\
\hline
\end{tabular}

\section{Establishment of Subjective Product Evaluation System}

\subsection{Overall Product Evaluation Framework}

In the past, when people evaluated a product, they usually focused on three dimensions of "aesthetics", "function", and "commerce". However, with the satisfaction of people's material life, "human-orientation" has become a concern, and whether a product is designed from the perspective of "human" has become more and more important [47,48]. Arthur J. Pulos, a famous American design educator, also emphasized that the fourth dimension of "humanity" in design is more important than other dimensions. Therefore, in this study, we take "aesthetic attribute", "functional attribute", "commercial attribute", and "human-oriented attribute" as the base point, excavate the evaluation indexes that affect product evaluation under these four attributes based on KE, and then construct the overall product evaluation framework based on AHP. In the overall product evaluation framework, each attribute is divided into two to four aspects, and each aspect contains two to four evaluation indexes, as shown in Figure 4, where evaluation indexes with gray background are subjective evaluation indexes, and evaluation indexes with colorless background are objective evaluation indexes.

\subsection{Weight Distribution of Each Level}

In the overall product evaluation framework, the AHP is used to calculate the weight of each element relative to the element above it, and the weight of each element in the lowest level relative to the element in the highest level, to obtain the overall product evaluation system. Specific steps are as follows:

1. Construct judgment matrix

Several experts judge the relative importance of each element by pairwise comparison of elements of the same level in the overall product evaluation framework, and construct judgment matrices, according to Table 1.

For example, in this study, the comparison matrix of "Material Texture $\mathrm{A}_{1}$ ", "Structure and Shape $\mathrm{A}_{2}$ ", and "Overall Coordination $\mathrm{A}_{3}$ " under "Visual Aspect $\mathrm{X}_{1}$ " is shown in Table 3. 


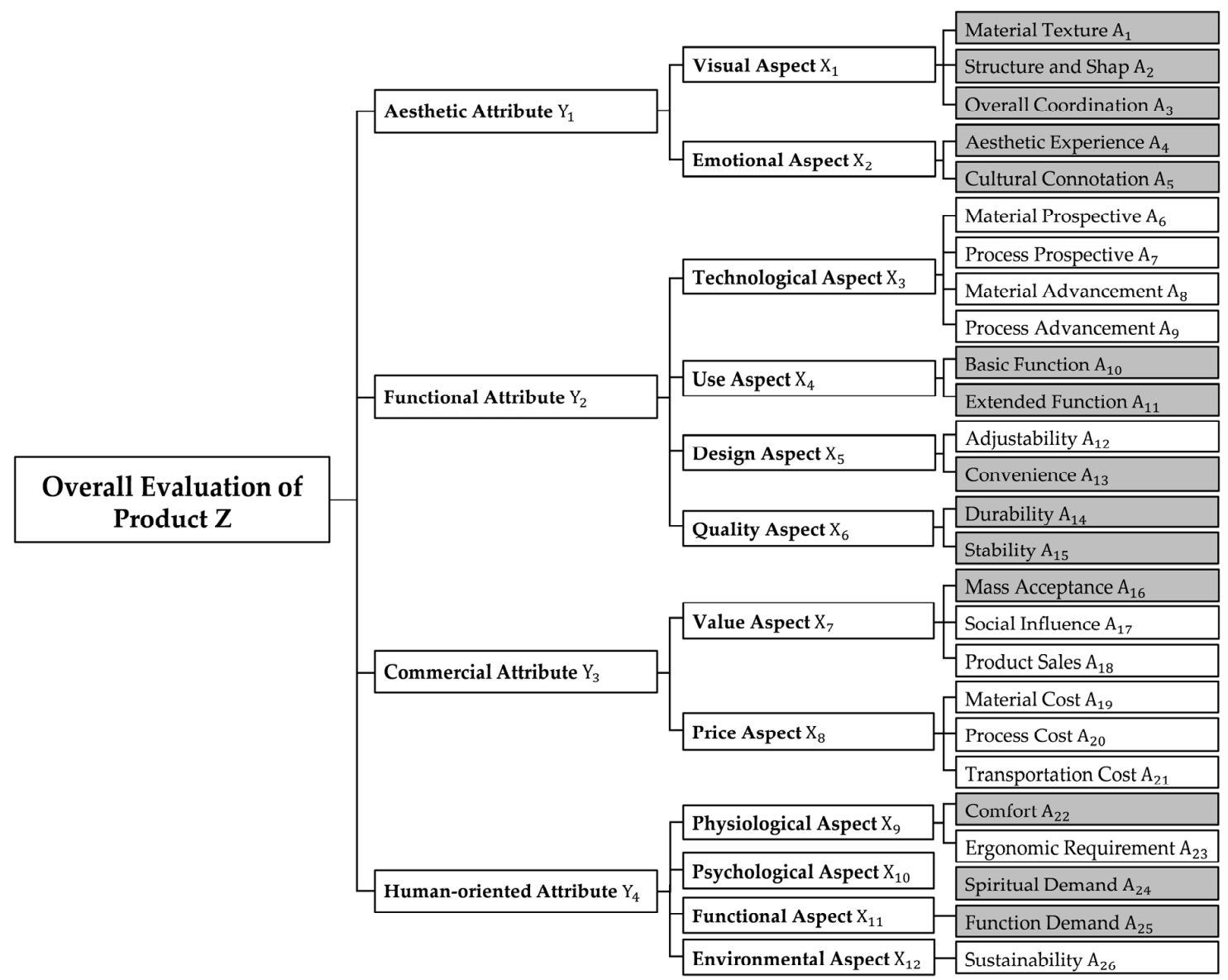

Figure 4. Overall product evaluation framework.

Table 3. The comparison matrix $R_{1}$.

\begin{tabular}{cccc}
\hline $\mathrm{X}_{1}$ & $\mathrm{~A}_{1}$ & $\mathrm{~A}_{2}$ & $\mathrm{~A}_{3}$ \\
\hline $\mathrm{A}_{1}$ & 1 & 1 & $1 / 5$ \\
$\mathrm{~A}_{2}$ & 1 & 1 & $1 / 5$ \\
$\mathrm{~A}_{3}$ & 5 & 5 & 1 \\
\hline
\end{tabular}

That is, $A=\left[\begin{array}{ccc}1 & 1 & 1 / 5 \\ 1 & 1 & 1 / 5 \\ 5 & 5 & 1\end{array}\right]$.

2 Normalize $A$ twice to obtain its eigenvector $W$, according to Equations (2) and (3)

That is, $W=\left[\begin{array}{l}0.1429 \\ 0.1429 \\ 0.7142\end{array}\right], W=\left(\begin{array}{lll}0.1429 & 0.1429 & 0.7142\end{array}\right)^{T}$.

3. Calculate the maximum eigenvalue $\lambda_{\max }$ of $A$, according to Equations (4) and (5)

$$
\begin{aligned}
& \text { We can get }\left[\begin{array}{ccc}
1 & 1 & 1 / 5 \\
1 & 1 & 1 / 5 \\
5 & 5 & 1
\end{array}\right] \cdot\left[\begin{array}{l}
1 / 7 \\
1 / 7 \\
5 / 7
\end{array}\right]=\left[\begin{array}{c}
3 / 7 \\
3 / 7 \\
15 / 7
\end{array}\right]=\left[\begin{array}{l}
0.4286 \\
0.4286 \\
2.1429
\end{array}\right]=\lambda_{\max } W, \\
& \lambda_{\max }=1 / 3 \cdot(0.4286 / 0.1429+0.4286 / 0.1429+2.1429 / 0.7142)=3 .
\end{aligned}
$$

4. Calculate $C R$ of $A$, according to Equations (6) and (7) and Table 2 
We can get $C I=(3-3) /(3-1), C R=\frac{(3-3) /(3-1)}{R I}=0 / 0.52=0<0.1$, that is, this matrix has an acceptable consistency.

5. Summary

Under the Visual Aspect, the weights of "Material Texture", "Structure and Shape" and "Overall Coordination" are $0.1429,0.1429$, and 0.7142 .

Following the above steps, we perform the remaining hierarchy single rankings and consistency checks, and obtain the following results.

The comparison matrix of "Aesthetic Experience $\mathrm{A}_{4}$ " and "Cultural Connotation $\mathrm{A}_{5}$ " under "Emotional Aspect $\mathrm{X}_{2}$ " is shown in Table 4.

Table 4. The comparison matrix $R_{2}$.

\begin{tabular}{ccc}
\hline $\mathrm{X}_{2}$ & $\mathrm{~A}_{4}$ & $\mathrm{~A}_{5}$ \\
\hline $\mathrm{A}_{4}$ & 1 & 3 \\
$\mathrm{~A}_{5}$ & $1 / 3$ & 1 \\
\hline
\end{tabular}

$W=\left[\begin{array}{l}0.7500 \\ 0.2500\end{array}\right], \lambda_{\max }=2, C I=0, C R=0<0.1$, this matrix has an acceptable consistency. That is, under the Emotional Aspect, the weights of "Aesthetic Experience" and "Cultural Connotation" are 0.7500 and 0.2500 .

The comparison matrix of "Material Prospective $\mathrm{A}_{6}$ ", "Process Prospective $\mathrm{A}_{7}$ ", "Material Advancement $\mathrm{A}_{8}$ " and "Process Advancement $\mathrm{A}_{9}$ " under "Technological Aspect $\mathrm{X}_{3}$ " is shown in Table 5.

Table 5. The comparison matrix $R_{3}$.

\begin{tabular}{ccccc}
\hline $\mathrm{X}_{3}$ & $\mathrm{~A}_{6}$ & $\mathrm{~A}_{7}$ & $\mathrm{~A}_{8}$ & $\mathrm{~A}_{9}$ \\
\hline $\mathrm{A}_{6}$ & 1 & 1 & $1 / 3$ & $1 / 3$ \\
$\mathrm{~A}_{7}$ & 1 & 1 & $1 / 3$ & $1 / 3$ \\
$\mathrm{~A}_{8}$ & 3 & 3 & 1 & 1 \\
$\mathrm{~A}_{9}$ & 3 & 3 & 1 & 1 \\
\hline
\end{tabular}

$W=\left[\begin{array}{l}0.1250 \\ 0.1250 \\ 0.3750 \\ 0.3750\end{array}\right], \lambda_{\max }=4, C I=0, C R=0<0.1$, this matrix has an acceptable consistency. That is, under the Technological Aspect, the weights of "Material Prospective $\mathrm{A}_{6}$ ", "Process Prospective $\mathrm{A}_{7}$ ", "Material Advancement $\mathrm{A}_{8}$ " and "Process Advancement A9" are 0.1250, 0.1250, 0.3750 and 0.3750.

The comparison matrix of "Basic Function $\mathrm{A}_{10}$ " and "Extended Function $\mathrm{A}_{11}$ " under "Use Aspect $\mathrm{X}_{4}$ "' is shown in Table 6.

Table 6. The comparison matrix $R_{4}$.

\begin{tabular}{ccc}
\hline $\mathrm{X}_{4}$ & $\mathrm{~A}_{10}$ & $\mathrm{~A}_{11}$ \\
\hline $\mathrm{A}_{10}$ & 1 & 5 \\
$\mathrm{~A}_{11}$ & $1 / 5$ & 1 \\
\hline
\end{tabular}

$W=\left[\begin{array}{l}0.8333 \\ 0.1667\end{array}\right], \lambda_{\max }=2, C I=0, C R=0<0.1$, this matrix has an acceptable consistency. That is, under the Use Aspect, the weights of "Basic Function $\mathrm{A}_{10}$ " and "Extended Function $\mathrm{A}_{11}$ " are 0.8333 and 0.1667 .

The comparison matrix of "Adjustability $\mathrm{A}_{12}$ " and "Convenience $\mathrm{A}_{13}$ " under "Design Aspect $\mathrm{X}_{5}$ " is shown in Table 7. 
Table 7. The comparison matrix $R_{5}$.

\begin{tabular}{ccc}
\hline $\mathrm{X}_{5}$ & $\mathrm{~A}_{12}$ & $\mathrm{~A}_{13}$ \\
\hline $\mathrm{A}_{12}$ & 1 & $1 / 5$ \\
$\mathrm{~A}_{13}$ & 5 & 1 \\
\hline
\end{tabular}

$W=\left[\begin{array}{l}0.1667 \\ 0.8333\end{array}\right], \lambda_{\max }=2, C I=0, C R=0<0.1$, this matrix has an acceptable consistency. That is, under the Design Aspect, the weights of "Adjustability $\mathrm{A}_{12}$ " and "Convenience $\mathrm{A}_{13}$ " are 0.1667 and 0.8333 .

The comparison matrix of "Durability $\mathrm{A}_{14}$ " and "Stability $\mathrm{A}_{15}$ " under "Quality Aspect $\mathrm{X}_{6}$ " is shown in Table 8.

Table 8. The comparison matrix $R_{6}$.

\begin{tabular}{ccc}
\hline $\mathrm{X}_{6}$ & $\mathrm{~A}_{14}$ & $\mathrm{~A}_{15}$ \\
\hline $\mathrm{A}_{14}$ & 1 & $1 / 5$ \\
$\mathrm{~A}_{15}$ & 5 & 1 \\
\hline
\end{tabular}

$W=\left[\begin{array}{l}0.1667 \\ 0.8333\end{array}\right], \lambda_{\max }=2, C I=0, C R=0<0.1$, this matrix has an acceptable consistency. That is, under the Quality Aspect, the weights of "Durability $\mathrm{A}_{14}$ " and "Stability $\mathrm{A}_{15}$ " are 0.1667 and 0.8333.

The comparison matrix of "Mass Acceptance $\mathrm{A}_{16}$ ", "Social Influence $\mathrm{A}_{17}$ " and "Product Sales $\mathrm{A}_{18}$ " under "Value Aspect $\mathrm{X}_{7}$ " is shown in Table 9.

Table 9. The comparison matrix $R_{7}$.

\begin{tabular}{cccc}
\hline $\mathrm{X}_{7}$ & $\mathrm{~A}_{16}$ & $\mathrm{~A}_{17}$ & $\mathrm{~A}_{18}$ \\
\hline $\mathrm{A}_{16}$ & 1 & $1 / 5$ & 3 \\
$\mathrm{~A}_{17}$ & 5 & 1 & 7 \\
$\mathrm{~A}_{18}$ & $1 / 3$ & $1 / 7$ & 1 \\
\hline
\end{tabular}

$W=\left[\begin{array}{l}0.1932 \\ 0.7235 \\ 0.0833\end{array}\right], \lambda_{\text {max }}=3.0660, C I=0.0330, C R=0.0569<0.1$, this matrix has an acceptable consistency. That is, under the Value Aspect, the weights of "Mass Acceptance $\mathrm{A}_{16}$ ", "Social Influence $\mathrm{A}_{17}$ " and "Product Sales $\mathrm{A}_{18}$ " are 0.1932, 0.7235 and 0.0833 .

The comparison matrix of "Material Cost $\mathrm{A}_{19}$ ", "Process Cost $\mathrm{A}_{20}$ " and "Transportation Cost $\mathrm{A}_{21}$ " under "Price Aspect $\mathrm{X}_{8}$ " is shown in Table 10.

Table 10. The comparison matrix $R_{8}$.

\begin{tabular}{cccc}
\hline $\mathrm{X}_{8}$ & $\mathrm{~A}_{19}$ & $\mathrm{~A}_{20}$ & $\mathrm{~A}_{21}$ \\
\hline $\mathrm{A}_{19}$ & 1 & 1 & 5 \\
$\mathrm{~A}_{20}$ & 1 & 1 & 5 \\
$\mathrm{~A}_{21}$ & $1 / 5$ & $1 / 5$ & 1 \\
\hline
\end{tabular}

$W=\left[\begin{array}{l}0.4545 \\ 0.4545 \\ 0.0909\end{array}\right], \lambda_{\max }=3, C I=0, C R=0<0.1$, this matrix has an acceptable consistency. That is, under the Price Aspect, the weights of "Material Cost $\mathrm{A}_{19}$ ", "Process Cost $\mathrm{A}_{20}$ " and "Transportation Cost $\mathrm{A}_{21}$ " are $0.4545,0.4545$ and 0.0909 .

The comparison matrix of "Comfort $\mathrm{A}_{22}$ " and "Ergonomic Requirement $\mathrm{A}_{23}$ " under "Physiological Aspect $\mathrm{X}_{9}$ " is shown in Table 11. 
Table 11. The comparison matrix $R_{9}$.

\begin{tabular}{ccc}
\hline $\mathrm{X}_{9}$ & $\mathrm{~A}_{22}$ & $\mathrm{~A}_{23}$ \\
\hline $\mathrm{A}_{22}$ & 1 & $1 / 5$ \\
$\mathrm{~A}_{23}$ & 1 & 1 \\
\hline
\end{tabular}

$W=\left[\begin{array}{l}0.1667 \\ 0.8333\end{array}\right], \lambda_{\max }=2, C I=0, C R=0<0.1$, this matrix has an acceptable consistency. That is, under the Physiological Aspect, the weights of "Comfort $\mathrm{A}_{22}$ " and "Ergonomic Requirement $\mathrm{A}_{23}$ " are 0.1667 and 0.8333 .

Under "Psychological Aspect $\mathrm{X}_{10}$ ", "Functional Aspect $\mathrm{X}_{11}$ " and "Environmental Aspect $\mathrm{X}_{12}$ ", there are only "Spiritual Demand $\mathrm{A}_{24}$ ", "Function Demand $\mathrm{A}_{25}$ " and "Sustainability $\mathrm{A}_{26}$ " respectively. That is, the weights of "Spiritual Demand $\mathrm{A}_{24}$ ", "Function Demand $\mathrm{A}_{25}$ " and "Sustainability $\mathrm{A}_{26}$ " relative to their above level are all 1.0000 .

The comparison matrix of "Visual Aspect $X_{1}$ " and "Emotional Aspect $X_{2}$ " under "Aesthetic Attribute $\mathrm{Y}_{1}$ " is shown in Table 12.

Table 12. The comparison matrix $R_{10}$.

\begin{tabular}{ccc}
\hline $\mathrm{Y}_{1}$ & $\mathrm{X}_{1}$ & $\mathrm{X}_{2}$ \\
\hline $\mathrm{X}_{1}$ & 1 & $1 / 3$ \\
$\mathrm{X}_{2}$ & 3 & 1 \\
\hline
\end{tabular}

$W=\left[\begin{array}{l}0.2500 \\ 0.7500\end{array}\right], \lambda_{\max }=2, C I=0, C R=0<0.1$, this matrix has an acceptable consistency. That is, under the Aesthetic Attribute, the weights of "Visual Aspect $\mathrm{X}_{1}$ " and "Emotional Aspect $\mathrm{X}_{2}$ " are 0.2500 and 0.7500 .

The comparison matrix of "Technological Aspect $X_{3}$ ", "Use Aspect $X_{4}$ ", "Design Aspect $X_{5}$ " and "Quality Aspect $\mathrm{X}_{6}$ " under "Functional Attribute $\mathrm{Y}_{2}$ " is shown in Table 13.

Table 13. The comparison matrix $R_{11}$.

\begin{tabular}{ccccc}
\hline $\mathrm{Y}_{2}$ & $\mathrm{X}_{3}$ & $\mathrm{X}_{4}$ & $\mathrm{X}_{5}$ & $\mathrm{X}_{6}$ \\
\hline $\mathrm{X}_{3}$ & 1 & $1 / 7$ & $1 / 4$ & $1 / 5$ \\
$\mathrm{X}_{4}$ & 7 & 1 & 5 & 4 \\
$\mathrm{X}_{5}$ & 4 & $1 / 5$ & 1 & $1 / 2$ \\
$\mathrm{X}_{6}$ & 5 & $1 / 4$ & 2 & 1 \\
\hline
\end{tabular}

$W=\left[\begin{array}{l}0.0535 \\ 0.5869 \\ 0.1425 \\ 0.2172\end{array}\right], \lambda_{\max }=4.1716, C I=0.0572, C R=0.0636<0.1$, this matrix has an acceptable consistency. That is, under the Functional Attribute, the weights of "Technological Aspect $\mathrm{X}_{3}$ ", "Use Aspect $X_{4}$ ", "Design Aspect $X_{5}$ " and "Quality Aspect $X_{6}$ " are 0.0535, 0.5869, 0.1425 and 0.2172.

The comparison matrix of "Value Aspect $X_{7}$ " and "Price Aspect $X_{8}$ " under "Commercial Attribute $\mathrm{Y}_{3}{ }^{\prime \prime}$ is shown in Table 14.

Table 14. The comparison matrix $R_{12}$.

\begin{tabular}{ccc}
\hline$Y_{3}$ & $X_{7}$ & $X_{8}$ \\
\hline$X_{7}$ & 1 & 9 \\
$X_{8}$ & $1 / 9$ & 1 \\
\hline
\end{tabular}


$W=\left[\begin{array}{l}0.9000 \\ 0.1000\end{array}\right], \lambda_{\max }=2, C I=0, C R=0<0.1$, this matrix has an acceptable consistency. That is, under the Commercial Attribute, the weights of "Value Aspect $X_{7}$ " and "Price Aspect $X_{8}$ " are 0.9000 and 0.1000 .

The comparison matrix of "Physiological Aspect $\mathrm{X}_{9}$ ", "Psychological Aspect $\mathrm{X}_{10}$ ", "Functional Aspect $X_{11}$ " and "Environmental Aspect $X_{12}$ " under "Human-oriented Attribute $Y_{4}$ " is shown in Table 15.

Table 15. The comparison matrix $R_{13}$.

\begin{tabular}{ccccc}
\hline $\mathrm{Y}_{4}$ & $\mathrm{X}_{9}$ & $\mathrm{X}_{10}$ & $\mathrm{X}_{11}$ & $\mathrm{X}_{12}$ \\
\hline $\mathrm{X}_{9}$ & 1 & $1 / 3$ & 1 & 5 \\
$\mathrm{X}_{10}$ & 3 & 1 & 3 & 6 \\
$\mathrm{X}_{11}$ & 1 & $1 / 3$ & 1 & 5 \\
$\mathrm{X}_{12}$ & $1 / 5$ & $1 / 6$ & $1 / 5$ & 1 \\
\hline
\end{tabular}

$W=\left[\begin{array}{l}0.2151 \\ 0.5131 \\ 0.2151 \\ 0.0567\end{array}\right], \lambda_{\max }=4.1077, C I=0.0359, C R=0.0399<0.1$, this matrix has an acceptable consistency. That is, under the Human-oriented Attribute, the weights of "Physiological Aspect $X_{9}$ ", "Psychological Aspect $\mathrm{X}_{10}$ ", "Functional Aspect $\mathrm{X}_{11}$ " and "Environmental Aspect $\mathrm{X}_{12}$ " are 0.2151, $0.5131,0.2151$ and 0.0567 .

The comparison matrix of "Aesthetic Attribute $Y_{1}$ ", "Functional Attribute $Y_{2}$ ", "Commercial Attribute $Y_{3}$ " and "Human-oriented Attribute $Y_{4}$ " under "Overall Evaluation of Product $Z$ " is shown in Table 16.

Table 16. The comparison matrix $R_{14}$.

\begin{tabular}{ccccc}
\hline $\mathrm{Z}$ & $\mathrm{Y}_{1}$ & $\mathrm{Y}_{2}$ & $\mathrm{Y}_{3}$ & $\mathrm{Y}_{4}$ \\
\hline $\mathrm{Y}_{1}$ & 1 & $1 / 5$ & $1 / 3$ & $1 / 5$ \\
$\mathrm{Y}_{2}$ & 5 & 1 & 3 & 1 \\
$\mathrm{Y}_{3}$ & 3 & $1 / 3$ & 1 & $1 / 3$ \\
$\mathrm{Y}_{4}$ & 5 & 1 & 3 & 1 \\
\hline
\end{tabular}

$$
W=\left[\begin{array}{l}
0.0687 \\
0.3889 \\
0.1535 \\
0.3889
\end{array}\right], \lambda_{\max }=4.0438, C I=0.0146, C R=0.01622<0.1 \text {, this matrix has an acceptable }
$$

consistency. That is, under the Overall Evaluation of Product, the weights of "Aesthetic Attribute $Y_{1}$ ", "Functional Attribute $\mathrm{Y}_{2}$ ", "Commercial Attribute $\mathrm{Y}_{3}$ " and "Human-oriented Attribute $\mathrm{Y}_{4}$ " are 0.0687, $0.3889,0.1535$ and 0.3889 .

Then, we integrate the calculation results of the weights into the overall product evaluation framework to obtain the overall product evaluation system, as shown in Figure 5.

In the overall product evaluation system, we can find that at the attribute level, the weight order of the four attributes is: Functional Attribute $=$ Human-oriented Attribute $>$ Commercial Attribute $>$ Aesthetic Attribute; at the evaluation index level, the weights of "Spiritual Demand", "Basic Function" and "Social Influence" are 0.1995, 0.1901 and 0.1000, ranking the top 3 in the weight ranking, while the weights of "Material Texture", "Structure and Shape", and "Transportation Cost" are 0.0025, 0.0025, and 0.0014 , ranking the last three in the weight ranking. 


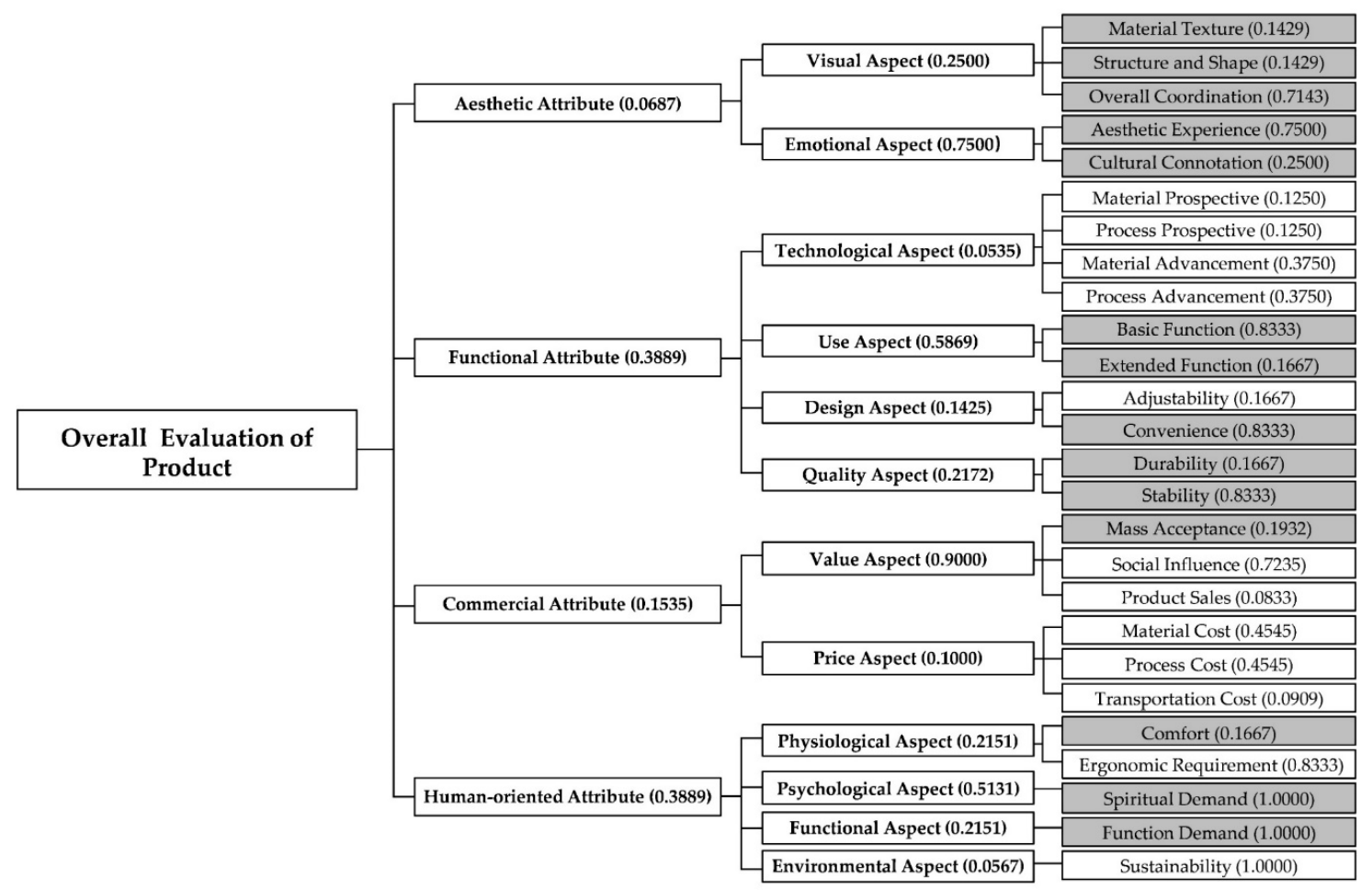

Figure 5. Overall product evaluation system. Each weight in the system is the weight of each element relative to the element above it. In this study, the weights of elements in the lowest level relative to the element in the highest level, through the hierarchy total ranking, according to the formula: weight of $\mathrm{A}$ $\times$ weight of $X \times$ weight of $Y=$ weight of $A$ relative to $Z$, can be obtained.

\subsection{Subjective Product Evaluation System}

The overall product evaluation system includes not only subjective evaluation indexes that can be scored by subjective feelings, but also objective evaluation indexes that can only be scored based on the objective information and data of products, rather than the customer's visual impression and subjective feelings of products in the purchase stage. Therefore, in order to establish a reasonable subjective product evaluation system, we need to separate objective and subjective evaluation indexes in the overall product evaluation system, and only retain the subjective evaluation indexes. The weights of the elements in the subjective product evaluation system are further calculated by the weights of the elements in the overall product evaluation system, according to the weight relationships between these elements, as shown in Figure 6.

In the subjective product evaluation system, we can find that at the attribute level, the weight order of the four attributes is: Functional Attribute $>$ Human-oriented Attribute $>$ Aesthetic Attribute > Commercial Attribute; at the evaluation index level, the weights of "Spiritual Demand", "Basic Function", and "Function Demand" are 0.2656, 0.2531, and 0.1113, ranking the top 3 in the weight ranking, and the total weight of these three indexes is 0.6300 , which is greater than 0.5000 , indicating these three indexes to some extent determine the subjective evaluation of a product, as shown in Table 17. 


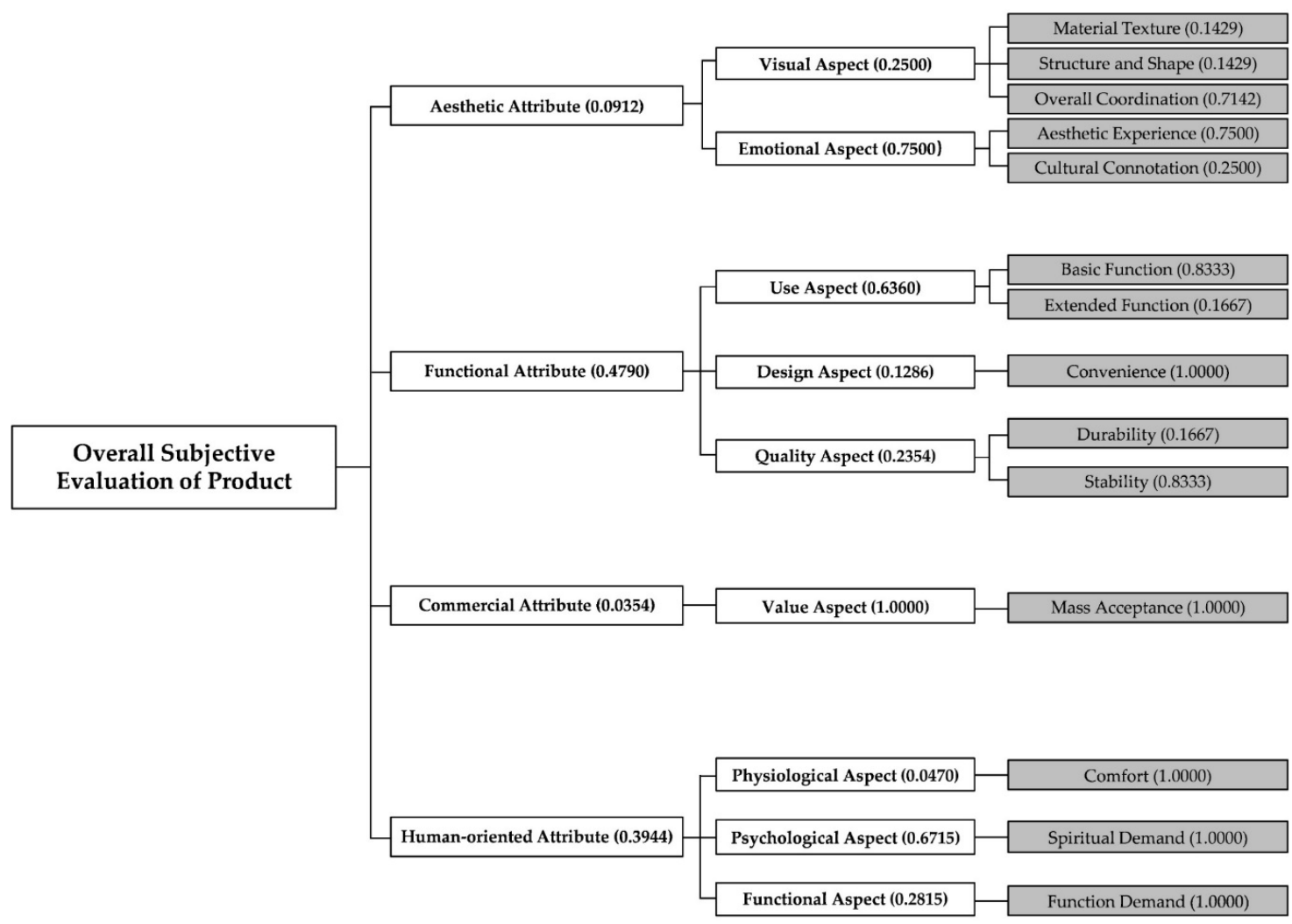

Figure 6. Subjective product evaluation system. Each weight in the system is the weight of each element relative to the element above it. In this study, the weights of elements in the lowest level relative to the element in the highest level, through the hierarchy total ranking, according to the formula: weight of $A$ $\times$ weight of $X \times$ weight of $Y=$ weight of $A$ relative to $Z$, can be obtained.

Table 17. Weights of subjective evaluation indexes.

\begin{tabular}{cc}
\hline Subjective Evaluation Index & Weight (Relative to Overall Subjective Evaluation) \\
\hline Spiritual Demand (Human-oriented Attribute) & 0.2656 \\
Basic Function (Functional Attribute) & 0.2531 \\
Function Demand (Human-oriented Attribute) & 0.1113 \\
Stability (Functional Attribute) & 0.0937 \\
Convenience (Functional Attribute) & 0.0615 \\
Aesthetic Experience (Aesthetic Attribute) & 0.0514 \\
Extended Function (Functional Attribute) & 0.0506 \\
Mass Acceptance (Commercial Attribute) & 0.0354 \\
Durability (Functional Attribute) & 0.0187 \\
Comfort (Human-oriented Attribute) & 0.0186 \\
Cultural Connotation (Aesthetic Attribute) & 0.0171 \\
Overall Coordination (Aesthetic Attribute) & 0.0163 \\
Material Texture (Aesthetic Attribute) & 0.0033 \\
Structure and Shape (Aesthetic Attribute) & 0.0033 \\
\hline Total & 1.0000 \\
\hline
\end{tabular}

Compared with the overall product evaluation system, in the subjective product evaluation system, the weights of "Aesthetic Attribute", "Functional Attribute", and "Human-oriented Attribute" have increased, while the weight of "Commercial Attribute" has decreased, and is less than that of "Aesthetic Attribute". At the same time, "Functional Attribute" occupies the largest weight in two evaluation systems, followed by "Human-oriented Attribute", and the weight of "Aesthetic Attribute" is smaller 
than "Commercial Attribute" in the overall product evaluation system, but greater than "Commercial Attribute" in the subjective product evaluation system. This means that both in the overall evaluation and subjective evaluation, "Functional Attribute" and "Human-oriented Attribute" of products are very important, and in the overall evaluation, the importance of "Commercial Attribute" is greater than that of "Aesthetic Attribute", but in the subjective evaluation, the importance of "Aesthetic Attribute" is greater than that of "Commercial Attribute", which may be related to the visibility of attributes: subjective evaluation depends largely on visual impressions and related associations caused by visual impressions, and "Aesthetic Attribute" performs better in visibility compared with "Commercial Attribute", so it has a greater importance than "Commercial Attribute" in subjective evaluation.

\section{Experimental Verification}

In order to confirm whether the subjective product evaluation system can be used to judge consumer's subjective evaluation of products, we verify it by experiment. The whole experiment includes experimental samples selection and processing, experiment implementation, experimental data processing and analysis, and verification analysis.

\subsection{Experimental Samples Selection and Processing}

In this experiment, we select 10 representative chair products as experimental samples. The feelings brought by visual stimulation can determine the subjective feelings of customers [49,50], and the color arrangements of some experimental samples are not fixed, so we provide experimental samples for the subjects in the form of monochrome pictures. The experimental samples are shown in Figure 7 (C01. Red and Blue Chair; C02.Wassily Armchair; C03. Barcelona Chair; C04. Armchair; C05. Butterfly Chair; C06. PP501 Chair; C07. Diamond Chair; C08. Lounge Chair; C09. Stackable Chair; C10. Djinn Seats).
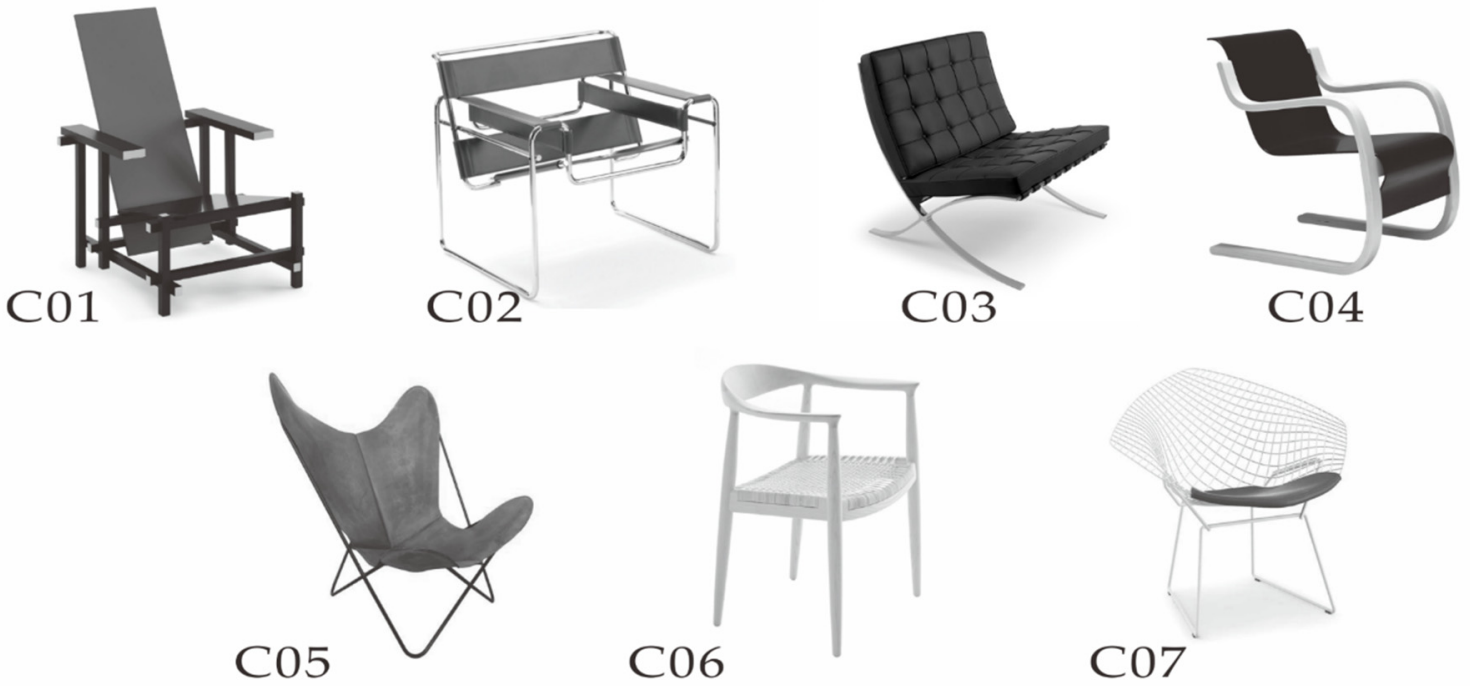

\section{C07}
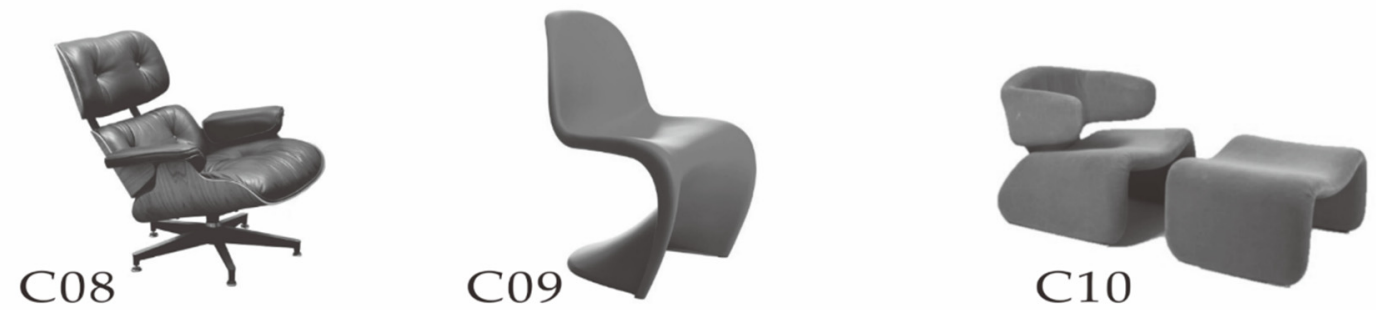

Figure 7. Experimental samples. 


\subsection{Experiment Implementation}

The experimental method is questionnaire survey. We provide each subject with a quiet and undisturbed questionnaire environment, a paper atlas (see Figure S1) and a paper questionnaire (see Table S1), and there is no time restriction for subjects to complete the questionnaire. The atlas contains pictures and other relevant information (such as material, size, etc.) of each experimental sample. The questionnaire consists of three parts: the first part is the basic information of the subjects, including gender, age, major background, and education background; the second part is the subjective evaluation of sample chairs, where each sample corresponds to 14 subjective evaluation questions, which are scored by Likert's 5-point scale, as shown in Table 18; the third part is comprehensive evaluation, where the subjects select the "favorite chair" and "least favorite chair" from 10 sample chairs, according to the subjective feelings. A total of 95 subjects participate in this experiment, and the valid questionnaire data come from 91 of them. The gender distribution of these subjects is 49 males $(53.8 \%)$ and 42 females (46.2\%); the ages of these subjects range from 20 to 55 years old, including $75(82.4 \%)$ from 20 to 30 years old, $8(8.8 \%)$ from 31 to 40 years old, and $8(8.8 \%)$ from 41 years old and above; the major backgrounds of these subjects are 41 (45.1\%) from design-related majors, $3(3.3 \%)$ from art-related majors, and $47(51.6 \%)$ from other majors; the education backgrounds of these subjects are $25(27.5 \%)$ with college/university education, $60(65.9 \%)$ with master/doctor education, and $6(6.6 \%)$ with other education.

Table 18. Subjective evaluation questions.

\begin{tabular}{|c|c|c|c|}
\hline Attribute & Aspect & Question of Subject Evaluation & Weak $\longleftrightarrow$ Strong \\
\hline \multirow{5}{*}{ Aesthetic Attribute } & \multirow{3}{*}{ Visual Aspect } & $\begin{array}{l}\text { Q01. What do you think of the } \\
\text { material of this chair? }\end{array}$ & 12345 \\
\hline & & $\begin{array}{l}\text { Q02. What do you think of the } \\
\text { structural shape of this chair? }\end{array}$ & 12345 \\
\hline & & $\begin{array}{l}\text { Q03. What do you think of the overall } \\
\text { coordination of this chair? }\end{array}$ & 12345 \\
\hline & \multirow{2}{*}{ Emotional Aspect } & $\begin{array}{l}\text { Q04. Does this chair give you a } \\
\text { pleasant psychological feeling? }\end{array}$ & 12345 \\
\hline & & $\begin{array}{l}\text { Q05. What do you think of the style } \\
\text { of this chair? }\end{array}$ & 12345 \\
\hline \multirow{5}{*}{ Functional Attribute } & \multirow{2}{*}{ Use Aspect } & $\begin{array}{l}\text { Q06. What do you think of the basic } \\
\text { function of this chair? }\end{array}$ & 12345 \\
\hline & & $\begin{array}{l}\text { Q07. What do you think of the } \\
\text { functional extensibility of this chair? }\end{array}$ & 12345 \\
\hline & Design Aspect & $\begin{array}{l}\text { Q08. What do you think of the } \\
\text { convenience of using this chair? }\end{array}$ & 12345 \\
\hline & \multirow{2}{*}{ Quality Aspect } & $\begin{array}{l}\text { Q09. What do you think of the } \\
\text { durability of this chair? }\end{array}$ & 12345 \\
\hline & & $\begin{array}{l}\text { Q10. What do you think of the } \\
\text { stability of this chair? }\end{array}$ & 12345 \\
\hline Commercial Attribute & Value Aspect & $\begin{array}{l}\text { Q11. Will you buy this chair if } \\
\text { economic conditions permit? }\end{array}$ & 12345 \\
\hline \multirow{3}{*}{ Human-oriented Attribute } & Physiological Aspect & $\begin{array}{l}\text { Q12. What do you think of the } \\
\text { comfort of this chair? }\end{array}$ & 12345 \\
\hline & Psychological Aspect & $\begin{array}{l}\text { Q13. Does this chair bring you } \\
\text { spiritual satisfaction? }\end{array}$ & 12345 \\
\hline & Functional Aspect & $\begin{array}{l}\text { Q14. Does this chair bring you } \\
\text { functional satisfaction? }\end{array}$ & 12345 \\
\hline
\end{tabular}




\subsection{Data Processing and Analysis}

\subsubsection{Subjective Evaluations of Experimental Samples}

Table 19 shows the subjects' subjective evaluations of each experimental sample. In Table 19, we can get the mean score of each chair under each subjective evaluation question and its standard deviation. For example, Q01: What do you think of the material of this chair? C03 has a mean score of 4.20 and a standard deviation of 0.819 on a 5-point scale; Q06: What do you think of the basic function of this chair? C08 has a mean score of 4.33 and a standard deviation of 0.746 on a 5-point scale. We import the questionnaire data of this experiment into SPSS for reliability and validity analysis. The results show that the Cronbach's Alpha coefficient of the questionnaire is 0.978, greater than 0.900 , indicating that the reliability of the questionnaire scale is good; for the analysis items of each chair sample in the questionnaire, the Kaiser-Meyer-Olkin (KMO) test coefficients are all greater than 0.800, and the P values of the Bartlett's sphericity test are all less than 0.010 , indicating that there is a correlation between the original data variables of the analysis items, and the data are suitable for factor analysis. In summary, the reliability coefficient of the questionnaire data is greater than 0.900 , and the reliability coefficient will not increase significantly after deleting individual analysis item, so the questionnaire data have high reliability and can be used for further analysis.

Table 19. Subjective evaluations of experimental samples.

\begin{tabular}{|c|c|c|c|c|c|c|c|c|c|c|}
\hline & $\mathrm{C} 01$ & $\mathrm{C} 02$ & $\mathrm{C} 03$ & $\mathrm{C} 04$ & $\mathrm{C} 05$ & C06 & $\mathrm{C} 07$ & $\mathrm{C} 08$ & C09 & C10 \\
\hline \multirow{2}{*}{ Q01 } & 3.04 & 3.21 & 4.20 & 3.63 & 3.57 & 3.89 & 3.14 & 4.11 & 3.23 & 3.92 \\
\hline & 1.144 & 1.038 & 0.819 & 1.018 & 1.066 & 1.016 & 1.111 & 0.936 & 1.193 & 1.088 \\
\hline \multirow{2}{*}{ Q02 } & 2.93 & 3.03 & 3.90 & 3.68 & 3.63 & 3.85 & 3.38 & 3.68 & 3.64 & 3.71 \\
\hline & 1.172 & 1.100 & 0.883 & 1.084 & 1.018 & 1.032 & 1.143 & 1.042 & 1.207 & 1.057 \\
\hline \multirow{2}{*}{ Q03 } & 3.03 & 3.21 & 3.82 & 3.68 & 3.56 & 4.04 & 3.20 & 3.78 & 3.59 & 3.65 \\
\hline & 1.169 & 1.101 & 0.984 & 0.976 & 0.968 & 0.918 & 1.088 & 0.998 & 1.211 & 1.026 \\
\hline \multirow{2}{*}{ Q04 } & 2.54 & 2.82 & 3.87 & 3.57 & 3.47 & 3.78 & 3.11 & 3.74 & 3.32 & 3.85 \\
\hline & 1.099 & 1.101 & 0.991 & 1.066 & 1.139 & 1.114 & 1.069 & 1.063 & 1.307 & 0.965 \\
\hline \multirow{2}{*}{ Q05 } & 3.46 & 3.35 & 3.87 & 3.65 & 3.68 & 3.68 & 3.60 & 3.55 & 3.77 & 3.70 \\
\hline & 1.302 & 1.242 & 1.013 & 1.015 & 1.094 & 1.134 & 1.219 & 1.067 & 1.292 & 1.049 \\
\hline \multirow{2}{*}{ Q06 } & 2.95 & 3.20 & 4.02 & 3.69 & 3.54 & 4.02 & 3.24 & 4.33 & 3.12 & 3.92 \\
\hline & 1.149 & 0.991 & 0.856 & 0.927 & 0.970 & 0.894 & 1.015 & 0.746 & 1.031 & 0.846 \\
\hline \multirow{2}{*}{ Q07 } & 2.77 & 2.92 & 3.46 & 3.11 & 2.98 & 3.38 & 3.04 & 3.78 & 2.90 & 3.88 \\
\hline & 1.175 & 1.108 & 0.911 & 0.983 & 1.064 & 1.172 & 1.074 & 1.020 & 1.165 & 1.052 \\
\hline \multirow{2}{*}{ Q08 } & 2.20 & 3.00 & 3.36 & 3.27 & 3.54 & 3.90 & 3.09 & 3.59 & 3.42 & 3.03 \\
\hline & 1.002 & 1.085 & 1.038 & 1.086 & 1.128 & 1.065 & 1.132 & 1.238 & 1.146 & 1.059 \\
\hline \multirow{2}{*}{ Q09 } & 3.12 & 3.10 & 3.46 & 3.35 & 3.05 & 4.01 & 3.01 & 3.99 & 3.35 & 3.74 \\
\hline & 1.290 & 1.155 & 1.057 & 1.037 & 0.970 & 0.863 & 1.090 & 0.888 & 1.233 & 0.964 \\
\hline \multirow{2}{*}{ Q10 } & 3.56 & 3.34 & 3.58 & 3.23 & 3.16 & 4.21 & 3.04 & 3.95 & 2.91 & 4.15 \\
\hline & 1.267 & 1.128 & 1.096 & 1.096 & 0.981 & 0.823 & 1.074 & 1.037 & 1.226 & 0.999 \\
\hline \multirow{2}{*}{ Q11 } & 1.97 & 2.30 & 3.56 & 2.99 & 3.00 & 3.57 & 2.75 & 3.64 & 2.65 & 3.41 \\
\hline & 1.187 & 1.188 & 1.318 & 1.321 & 1.274 & 1.284 & 1.244 & 1.140 & 1.328 & 1.273 \\
\hline \multirow{2}{*}{ Q12 } & 2.11 & 2.84 & 4.05 & 3.42 & 3.58 & 3.58 & 3.10 & 4.43 & 2.69 & 4.11 \\
\hline & 0.948 & 1.003 & 0.935 & 0.978 & 1.076 & 1.023 & 1.146 & 0.791 & 1.161 & 0.960 \\
\hline \multirow{2}{*}{ Q13 } & 2.67 & 2.74 & 3.82 & 3.26 & 3.23 & 3.63 & 3.02 & 3.78 & 2.99 & 3.80 \\
\hline & 1.155 & 1.281 & 1.039 & 1.143 & 1.126 & 1.189 & 1.135 & 0.987 & 1.243 & 0.969 \\
\hline \multirow{2}{*}{ Q14 } & 2.59 & 2.80 & 3.81 & 3.42 & 3.47 & 3.81 & 3.13 & 4.29 & 2.97 & 3.87 \\
\hline & 1.192 & 1.077 & 0.988 & 1.023 & 0.993 & 0.953 & 1.098 & 0.834 & 1.149 & 1.024 \\
\hline
\end{tabular}




\subsubsection{Effects from Social Factors on Subjective Evaluation}

For subjects of different genders, because there are two groups of genders, we use "gender" as the influencing factor to conduct the independent sample $t$ test (T-Test). The differences in subjective evaluation of samples from different genders are shown in Table 20.

Table 20. Analysis of gender differences in sample subjective evaluation (T-Test).

\begin{tabular}{|c|c|c|c|c|c|c|c|}
\hline Sample & Question & Gender & $\mathbf{N}$ & Mean Score & Std. Deviation & $\mathbf{T}$ & Comparison \\
\hline \multirow{8}{*}{$\mathrm{C} 01$} & \multirow{2}{*}{ Q02 } & Male & 49 & 2.51 & 1.063 & \multirow[b]{2}{*}{$-4.030 * *$} & \multirow{2}{*}{1} \\
\hline & & Female & 42 & 3.43 & 1.107 & & \\
\hline & \multirow{2}{*}{ Q03 } & Male & 49 & 2.69 & 1.122 & \multirow{2}{*}{$-3.133^{* *}$} & \multirow{2}{*}{$2>1$} \\
\hline & & Female & 42 & 3.43 & 1.107 & & \\
\hline & \multirow{2}{*}{ Q04 } & Male & 49 & 2.27 & 0.908 & \multirow{2}{*}{$-2.646 *$} & \multirow{2}{*}{$2>1$} \\
\hline & & Female & 42 & 2.86 & 1.221 & & \\
\hline & \multirow{2}{*}{ Q09 } & Male & 49 & 2.73 & 1.303 & \multirow[b]{2}{*}{$-3.245^{* *}$} & \multirow{2}{*}{$2>1$} \\
\hline & & Female & 42 & 3.57 & 1.129 & & \\
\hline \multirow{2}{*}{$\mathrm{CO2}$} & \multirow{2}{*}{ Q09 } & Male & 49 & 2.88 & 1.184 & \multirow{2}{*}{$-2.007^{*}$} & \multirow{2}{*}{$2>1$} \\
\hline & & Female & 42 & 3.36 & 1.078 & & \\
\hline \multirow{2}{*}{$\mathrm{C} 04$} & \multirow{2}{*}{ Q08 } & Male & 49 & 3.51 & 1.063 & \multirow{2}{*}{$2.286^{*}$} & \multirow{2}{*}{$1>2$} \\
\hline & & Female & 42 & 3.00 & 1.059 & & \\
\hline
\end{tabular}

Note: significance: ${ }^{*} p<0.05,{ }^{* *} p<0.01$; Gender: 1 . male, 2 . female.

For subjects of different ages, because there are three groups of ages, we use "age" as the influencing factor to conduct the one-way analysis of variance (ANOVA). The differences in subjective evaluation of samples from different ages are shown in Table 21.

Table 21. Analysis of age differences in sample subjective evaluation (ANOVA).

\begin{tabular}{|c|c|c|c|c|c|c|c|c|c|c|}
\hline Sample & Evaluation Attribute & & $\begin{array}{l}\text { Sum of } \\
\text { Squares }\end{array}$ & df & Age & $\mathbf{N}$ & $\begin{array}{l}\text { Mean } \\
\text { Score }\end{array}$ & $\begin{array}{c}\text { Std. } \\
\text { Deviation }\end{array}$ & $\mathbf{F}$ & Comparison \\
\hline \multirow{6}{*}{$\mathrm{C} 03$} & \multirow{3}{*}{$\begin{array}{l}\text { Commercial } \\
\text { Attribute (Mean } \\
\text { score of Q11) }\end{array}$} & Between groups & 16.988 & 2 & 1 & 75 & 3.76 & 1.228 & & \\
\hline & & Within groups & 139.430 & 88 & 2 & 8 & 2.63 & 1.188 & $5.361^{* *}$ & $1>2,1>3$ \\
\hline & & Total & 156.418 & 90 & 3 & 8 & 2.63 & 1.598 & & \\
\hline & \multirow{3}{*}{$\begin{array}{l}\text { Human-oriented } \\
\text { Attribute (Mean } \\
\text { score of Q12-Q14) }\end{array}$} & Between groups & 7.629 & 2 & 1 & 75 & 4.03 & 0.793 & & \\
\hline & & Within groups & 62.747 & 88 & 2 & 8 & 3.25 & 1.020 & $5.350 * *$ & $1>2,1>3$ \\
\hline & & Total & 70.376 & 90 & 3 & 8 & 3.29 & 1.133 & & \\
\hline \multirow{9}{*}{$\mathrm{C} 05$} & \multirow{3}{*}{$\begin{array}{l}\text { Aesthetic Attribute } \\
\text { (Mean score of } \\
\text { Q01-Q05) }\end{array}$} & Between groups & 7.628 & 2 & 1 & 75 & 3.70 & 0.829 & & \\
\hline & & Within groups & 65.384 & 88 & 2 & 8 & 3.30 & 0.807 & $5.133 * *$ & $1>3$ \\
\hline & & Total & 73.012 & 90 & 3 & 8 & 2.73 & 1.190 & & \\
\hline & \multirow{3}{*}{$\begin{array}{c}\text { Functional Attribute } \\
\text { (Mean score of } \\
\text { Q06-Q10) }\end{array}$} & Between groups & 5.006 & 2 & 1 & 75 & 3.33 & 0.767 & & \\
\hline & & Within groups & 55.159 & 88 & 2 & 8 & 3.30 & 0.676 & $3.993 *$ & $1>3$ \\
\hline & & Total & 60.165 & 90 & 3 & 8 & 2.50 & 1.095 & & \\
\hline & \multirow{3}{*}{$\begin{array}{l}\text { Human-oriented } \\
\text { Attribute (Mean } \\
\text { score of Q12-Q14) }\end{array}$} & Between groups & 10.125 & 2 & 1 & 75 & 3.56 & 0.892 & & \\
\hline & & Within groups & 72.383 & 88 & 2 & 8 & 3.17 & 0.816 & $6.155^{* *}$ & $1>3$ \\
\hline & & Total & 82.508 & 90 & 3 & 8 & 2.42 & 1.123 & & \\
\hline \multirow{3}{*}{$\mathrm{C} 07$} & \multirow{3}{*}{$\begin{array}{c}\text { Functional Attribute } \\
\text { (Mean score of } \\
\text { Q06-Q10) }\end{array}$} & Between groups & 5.776 & 2 & 1 & 75 & 3.16 & 0.829 & & \\
\hline & & Within groups & 65.995 & 88 & 2 & 8 & 3.20 & 1.009 & 3.851 * & $1>3,2>3$ \\
\hline & & Total & 71.771 & 90 & 3 & 8 & 2.28 & 1.069 & & \\
\hline \multirow{3}{*}{$\mathrm{C} 09$} & \multirow{3}{*}{$\begin{array}{l}\text { Functional Attribute } \\
\text { (Mean score of } \\
\text { Q06-Q10) }\end{array}$} & Between groups & 8.962 & 2 & 1 & 75 & 3.28 & 0.873 & & \\
\hline & & Within groups & 75.077 & 88 & 2 & 8 & 2.63 & 1.000 & $5.252 * *$ & $1>3$ \\
\hline & & Total & 84.040 & 90 & 3 & 8 & 2.33 & 1.296 & & \\
\hline \multirow{3}{*}{ C10 } & \multirow{3}{*}{$\begin{array}{c}\text { Functional Attribute } \\
\text { (Mean score of } \\
\text { Q06-Q10) }\end{array}$} & Between groups & 4.299 & 2 & 1 & 75 & 3.85 & 0.657 & & \\
\hline & & Within groups & 48.346 & 88 & 2 & 8 & 3.30 & 1.176 & 3.913 * & $1>3$ \\
\hline & & Total & 52.645 & 90 & 3 & 8 & 3.25 & 0.978 & & \\
\hline
\end{tabular}

Note: Significance: ${ }^{*} p<0.05,{ }^{* *} p<0.01$; Age: $1.20-30$ years old, 2. 31-40 years old, 3. 40 years old and above. 
For subjects of different major backgrounds, because there are three groups of majors, we use "major background" as the influencing factor to conduct the one-way analysis of variance (ANOVA). The differences in subjective evaluation of samples from different major backgrounds are shown in Table 22.

Table 22. Analysis of major background differences in sample subjective evaluation (ANOVA).

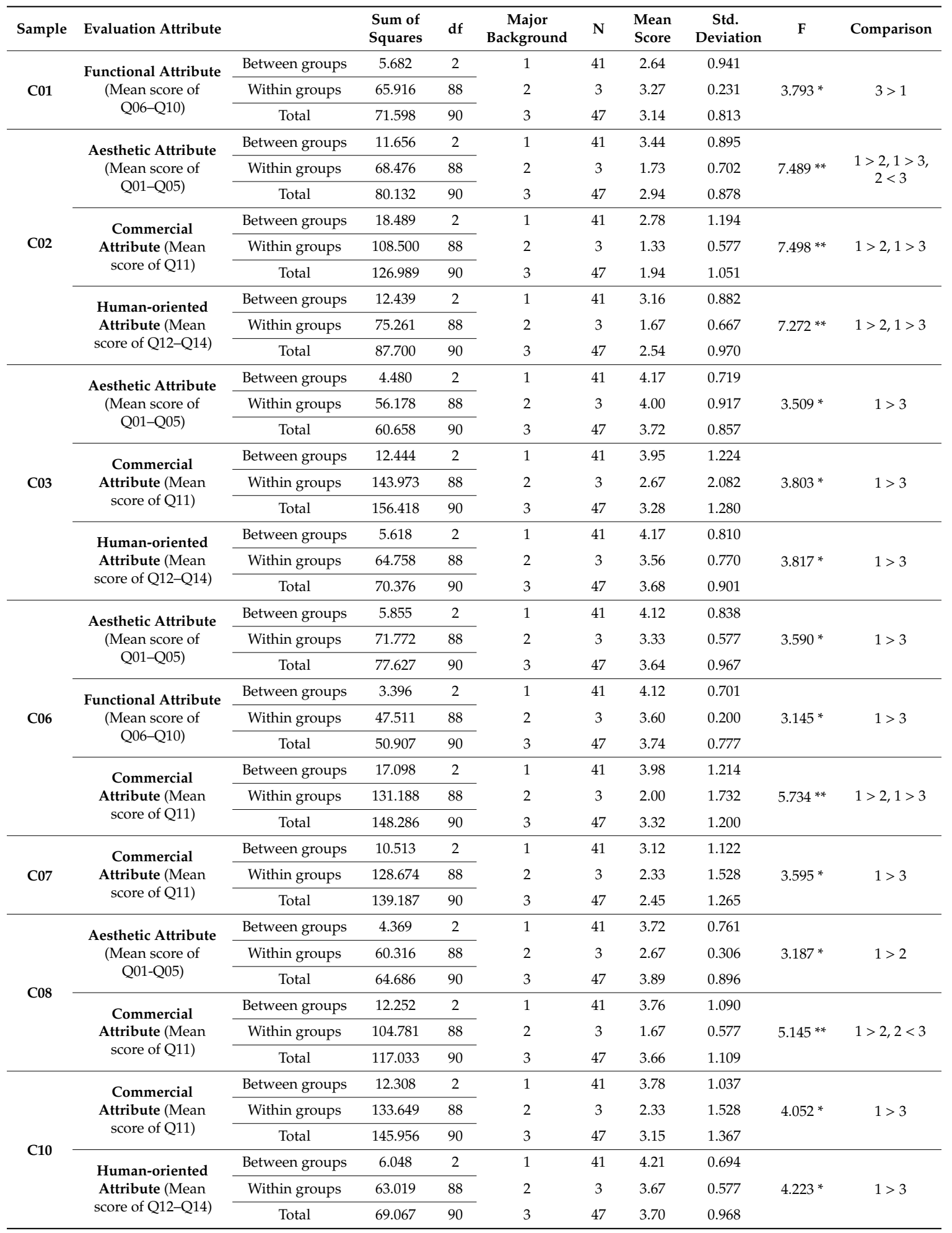

Note: significance: ${ }^{*} p<0.05,{ }^{* *} p<0.01$; major background: 1 . design-related majors, 2 . art-related majors, 3 . other majors. 
For subjects of different education backgrounds, because there are three groups of education backgrounds, we use "education background" as the influencing factor to conduct the one-way analysis of variance (ANOVA). The differences in subjective evaluation of samples from different education backgrounds are shown in Table 23.

Table 23. Analysis of education background differences in sample subjective evaluation (ANOVA).

\begin{tabular}{|c|c|c|c|c|c|c|c|c|c|c|}
\hline Sample & Question & & $\begin{array}{l}\text { Sum of } \\
\text { Squares }\end{array}$ & df & $\begin{array}{c}\text { Education } \\
\text { Background }\end{array}$ & $\mathbf{N}$ & Mean Score & $\begin{array}{c}\text { Std. } \\
\text { Deviation }\end{array}$ & F & Comparison \\
\hline \multirow{15}{*}{$\mathrm{C} 01$} & \multirow{3}{*}{ Q07 } & Between groups & 11.297 & 2 & 1 & 25 & 3.28 & 1.208 & \multirow{3}{*}{$4.404 *$} & \multirow{3}{*}{$1>2$} \\
\hline & & Within groups & 112.857 & 88 & 2 & 60 & 2.52 & 1.049 & & \\
\hline & & Total & 124.154 & 90 & 3 & 6 & 3.17 & 1.602 & & \\
\hline & \multirow{3}{*}{ Q08 } & Between groups & 10.110 & 2 & 1 & 25 & 2.24 & 1.052 & \multirow{3}{*}{$4.750 *$} & \multirow{3}{*}{$1<3,2<3$} \\
\hline & & Within groups & 139.560 & 88 & 2 & 60 & 2.07 & 0.841 & & \\
\hline & & Total & 149.670 & 90 & 3 & 6 & 3.33 & 1.633 & & \\
\hline & \multirow{3}{*}{ Q11 } & Between groups & 9.484 & 2 & 1 & 25 & 1.80 & 1.041 & \multirow{3}{*}{3.554 * } & \multirow{3}{*}{$1<3,2<3$} \\
\hline & & Within groups & 117.417 & 88 & 2 & 60 & 1.92 & 1.139 & & \\
\hline & & Total & 126.901 & 90 & 3 & 6 & 3.17 & 1.722 & & \\
\hline & \multirow{3}{*}{ Q12 } & Between groups & 13.668 & 2 & 1 & 25 & 2.20 & 0.764 & \multirow{3}{*}{$8.945^{* *}$} & \multirow{3}{*}{$1<3,2<3$} \\
\hline & & Within groups & 67.233 & 88 & 2 & 60 & 1.93 & 0.841 & & \\
\hline & & Total & 80.901 & 90 & 3 & 6 & 3.50 & 1.517 & & \\
\hline & \multirow{3}{*}{ Q14 } & Between groups & 10.949 & 2 & 1 & 25 & 2.68 & 1.108 & \multirow{3}{*}{4.117 * } & \multirow{3}{*}{$1<3,2<3$} \\
\hline & & Within groups & 117.007 & 88 & 2 & 60 & 2.43 & 1.125 & & \\
\hline & & Total & 127.956 & 90 & 3 & 6 & 3.83 & 1.602 & & \\
\hline \multirow{3}{*}{$\mathrm{C} 02$} & \multirow{3}{*}{ Q09 } & Between groups & 8.710 & 2 & 1 & 25 & 3.60 & 1.291 & \multirow{3}{*}{$3.440 *$} & \multirow{3}{*}{$1>2$} \\
\hline & & Within groups & 111.400 & 88 & 2 & 60 & 2.90 & 1.020 & & \\
\hline & & Total & 120.110 & 90 & 3 & 6 & 3.00 & 1.414 & & \\
\hline \multirow{3}{*}{$\mathrm{C} 03$} & & Between groups & 12.160 & 2 & 1 & 25 & 3.88 & 1.054 & & \\
\hline & Q08 & Within groups & 84.873 & 88 & 2 & 60 & 3.10 & 0.969 & $6.304 *$ & $1>2$ \\
\hline & & Total & 97.033 & 90 & 3 & 6 & 3.83 & 0.753 & & \\
\hline & & Between groups & 7.974 & 2 & 1 & 25 & 4.08 & 0.909 & & \\
\hline & Q05 & Within groups & 84.773 & 88 & 2 & 60 & 3.53 & 0.982 & $4.139 *$ & $1>2,1>3$ \\
\hline$C_{0}$ & & Total & 92.747 & 90 & 3 & 6 & 3.00 & 1.265 & & \\
\hline $\mathrm{CO4}$ & & Between groups & 8.334 & 2 & 1 & 25 & 3.60 & 0.913 & & \\
\hline & Q07 & Within groups & 78.567 & 88 & 2 & 60 & 2.93 & 0.918 & $4.668 *$ & $1>2$ \\
\hline & & Total & 86.901 & 90 & 3 & 6 & 2.83 & 1.329 & & \\
\hline & & Between groups & 10.141 & 2 & 1 & 25 & 3.88 & 0.971 & & \\
\hline & Q04 & Within groups & 106.540 & 88 & 2 & 60 & 3.40 & 1.123 & 4.188 * & $1>3$ \\
\hline & & Total & 116.681 & 90 & 3 & 6 & 2.50 & 1.378 & & \\
\hline & & Between groups & 7.659 & 2 & 1 & 25 & 3.88 & 1.013 & & \\
\hline & Q06 & Within groups & 76.957 & 88 & 2 & 60 & 3.48 & 0.854 & 4.379 * & $1>3,2>3$ \\
\hline 805 & & Total & 84.615 & 90 & 3 & 6 & 2.67 & 1.366 & & \\
\hline cos & & Between groups & 11.713 & 2 & 1 & 25 & 3.56 & 0.961 & & \\
\hline & Q07 & Within groups & 90.243 & 88 & 2 & 60 & 2.75 & 0.968 & $5.711 * *$ & $1>2$ \\
\hline & & Total & 101.956 & 90 & 3 & 6 & 2.83 & 1.602 & & \\
\hline & & Between groups & 6.765 & 2 & 1 & 25 & 3.80 & 0.957 & & \\
\hline & Q14 & Within groups & 81.917 & 88 & 2 & 60 & 3.42 & 0.926 & $3.634 *$ & $1>3$ \\
\hline & & Total & 88.681 & 90 & 3 & 6 & 2.67 & 1.366 & & \\
\hline & & Between groups & 9.888 & 2 & 1 & 25 & 3.80 & 1.225 & & \\
\hline $\mathrm{C} 06$ & Q07 & Within groups & 113.650 & 88 & 2 & 60 & 3.15 & 1.117 & $3.828 *$ & $1>2$ \\
\hline & & Total & 123.538 & 90 & 3 & 6 & 4.00 & 0.894 & & \\
\hline & & Between groups & 7.818 & 2 & 1 & 25 & 3.52 & 1.005 & & \\
\hline $\mathrm{C} 07$ & Q07 & Within groups & 96.007 & 88 & 2 & 60 & 2.87 & 0.999 & $3.583 *$ & $1>2$ \\
\hline & & Total & 103.824 & 90 & 3 & 6 & 2.83 & 1.602 & & \\
\hline
\end{tabular}


Table 23. Cont.

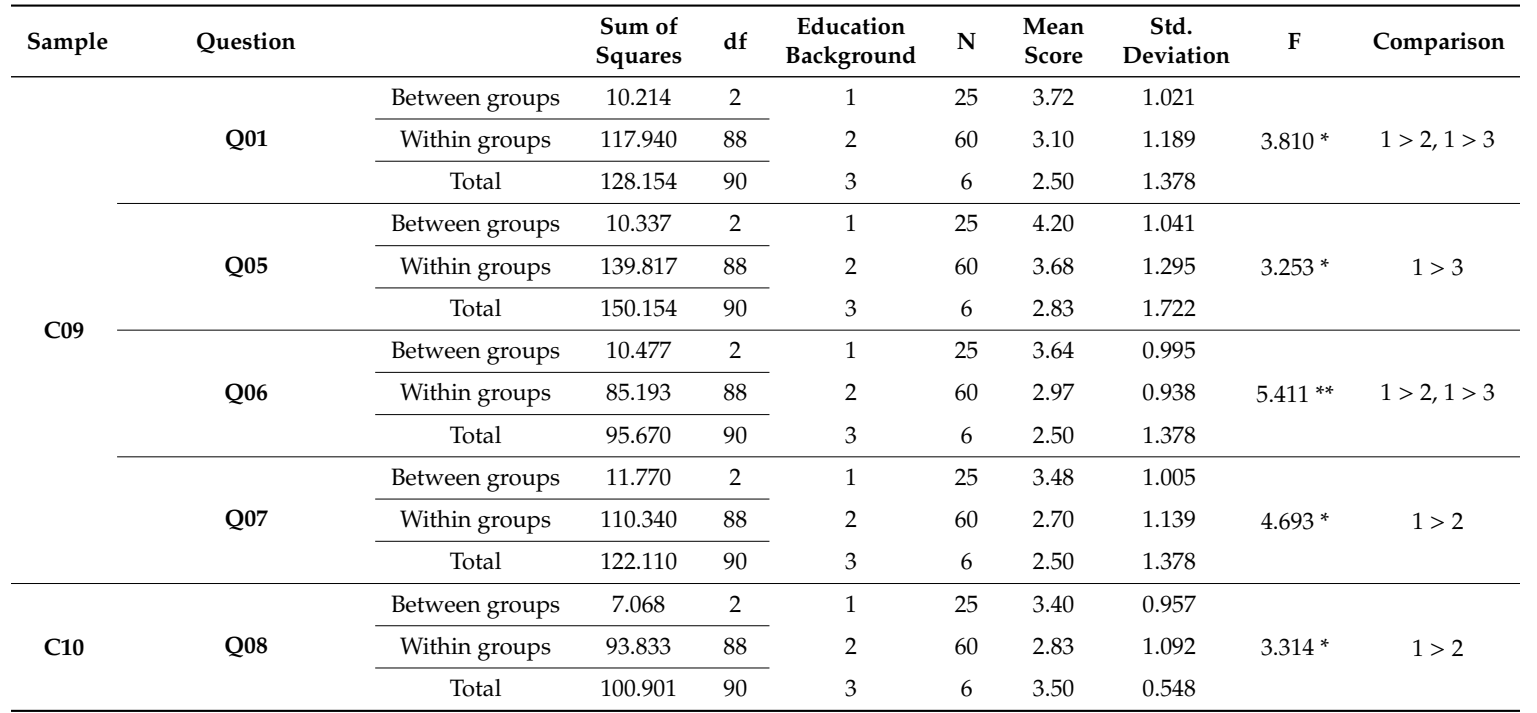

Note: significance: ${ }^{*} p<0.05,{ }^{* *} p<0.01$; education background: 1 . college/university education, 2 . master/doctor education, 3 . other education.

Through the above difference analysis, we can find that differences in social factors do cause differences in some subjective evaluations of some experimental samples. It is embodied as follows: for subjects of different genders, when there are differences in the evaluation of subjective evaluation indexes of experimental samples, the female subjects usually have higher recognitions of these subjective evaluation indexes than the male subjects; for subjects of different ages, when there are differences in the evaluation of subjective evaluation indexes of experimental samples, the subjects aged 20-30 usually have higher recognitions of these subjective evaluation indexes than those aged over 30; for subjects with different major backgrounds, when there are differences in the evaluation of subjective evaluation indexes of experimental samples, the subjects from design-related majors usually have higher recognitions of these subjective evaluation indexes than those from non-design-related majors; for subjects with different education backgrounds, when there are differences in the evaluation of subjective evaluation indexes of experimental samples, the subjects with other education usually have higher recognitions of these subjective evaluation indexes than those with college/university and master/doctor education. However, these differences do not affect the comparison between the mean scores of each subjective evaluation index of each experimental sample.

\subsubsection{Verification Analysis}

According to the formula: overall subjective evaluation = score of $A_{1} \times$ weight of $A_{1}+\ldots+$ score of $A_{n} \times$ weight of $A_{n}$, we can get the overall subjective evaluation of each experimental sample. The overall subjective evaluations of experimental samples are shown in Table 24.

At the same time, we collate and display the survey results of the comprehensive evaluation part of the questionnaire in bar charts, as shown in Figure 8.

In Figure 8a, the statistical result of the subjects" "favorite chair" is that C03 has the highest identification degree, with 23 subjects $(25.3 \%)$ choosing this option; followed by C08, with 22 subjects (24.2\%) choosing this option; and then C06, with 15 subjects (16.5\%) choosing this option; and then C10, with 14 subjects $(15.4 \%)$ choosing this option. C02 has the lowest identification degree, with no one choosing this option; followed by $\mathrm{C} 01$, with only 1 subject $(1.1 \%)$ choosing this option. 
Table 24. Overall subjective evaluations of experimental samples.

\begin{tabular}{cc}
\hline Experimental Sample & Overall Subject Evaluation \\
\hline C01 & 2.779 \\
C02 03 & 2.962 \\
C03 04 & 3.794 \\
C05 & 3.404 \\
C06 & 3.358 \\
C07 08 & 3.828 \\
C08 09.106 \\
C10 & 3.986 \\
\end{tabular}

In Figure $8 \mathrm{~b}$, the statistical result of the subjects" "least favorite chair" is that C01 has the highest identification degree, with 27 subjects (29.7\%) choosing this option; followed by C02, with 18 subjects $(19.8 \%)$ choosing this option; and then C07, with 14 subjects $(15.4 \%)$ choosing this option; and then C09, with 13 subjects $(14.3 \%)$ choosing this option. C06 has the lowest identification degree, with only 1 subject $(1.1 \%)$ choosing this option; followed by $\mathrm{C} 03$, with 2 subjects $(2.2 \%)$ choosing this option. At the same time, $\mathrm{C} 04$ and $\mathrm{C} 10$ have the same identification degree.

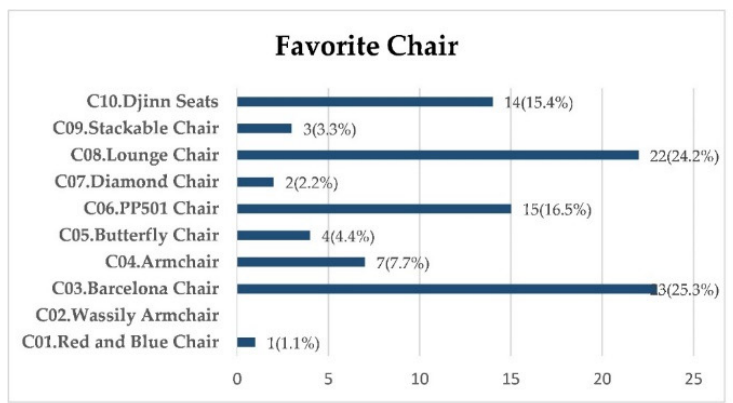

(a)

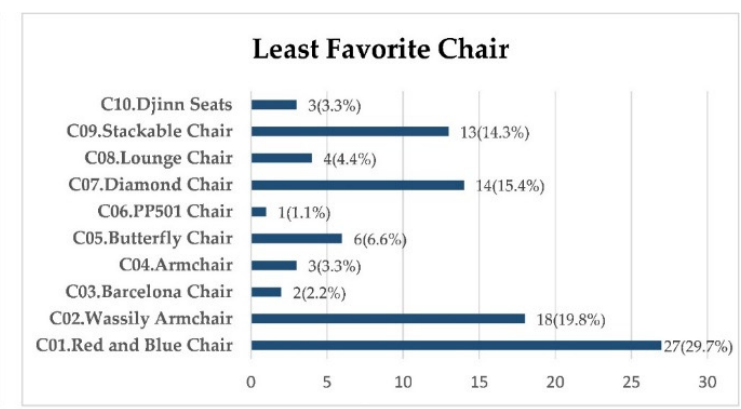

(b)

Figure 8. Comprehensive evaluation of experimental samples. (a) The statistical result of "favorite chair" in comprehensive evaluation. (b) The statistical result of "least favorite chair" in comprehensive evaluation.

According to the survey results of comprehensive evaluation, we divide the identification degree of "favorite chair" into ten levels and the identification degree of "least favorite chair" into 9 levels (because, for "least favorite chair", C04 and C10 have the same identification degree). Then, we put the overall subjective evaluation of samples and the identification degree level of samples in comprehensive evaluation in the same coordinate system. In this coordinate system, the horizontal axis is the identification degree level in comprehensive evaluation (the higher the level, the higher the identification degree); the vertical axis is the overall subjective evaluation (the higher the score, the higher the evaluation). Each coordinate point is composed of the identification degree level and the overall subjective evaluation of the experimental sample at this identification degree level, and then these coordinate points together constitute a scatterplot of the relationship between the overall subjective evaluation and comprehensive evaluation of the experimental samples, as shown in Figure 9. 


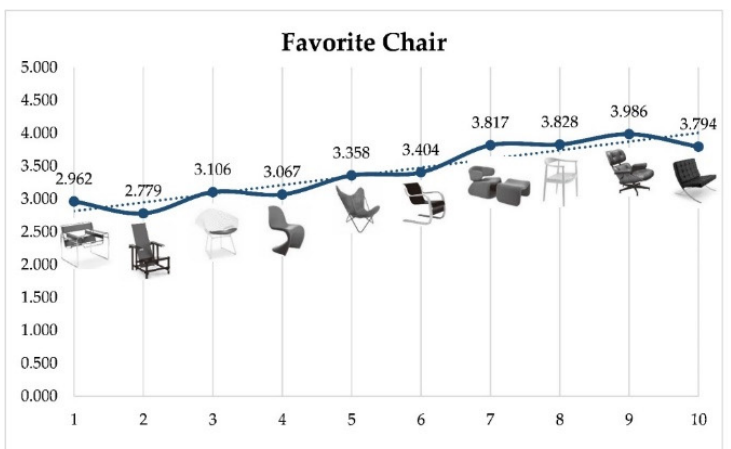

(a)

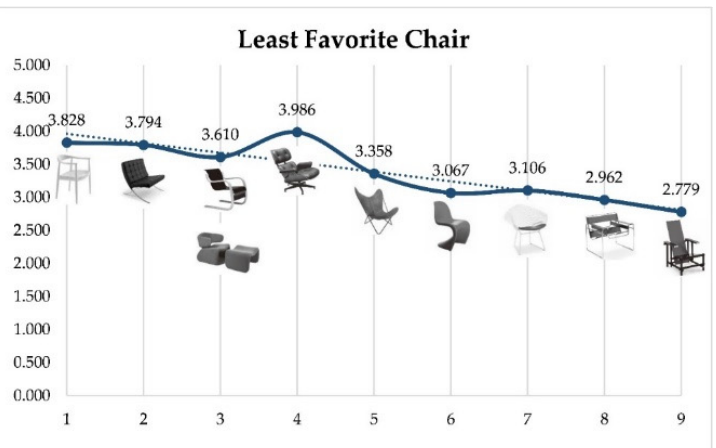

(b)

Figure 9. Relationship between overall subjective evaluation and comprehensive evaluation. (a) The relationship between the overall subjective evaluation and the level of "favorite chair" in comprehensive evaluation. (b) The relationship between the overall subjective evaluation and the level of "least favorite chair" in comprehensive evaluation.

In Figure 9a, we can find that the overall subjective evaluation is basically positively correlated with the level of "favorite chair", that is, the more popular the chair is in the comprehensive evaluation, the higher the overall subjective evaluation will be. In Figure 9b, we can find that the overall subjective evaluation is basically negatively correlated with the level of "least favorite chair", that is, the less popular the chair is in the comprehensive evaluation, the lower the overall subjective evaluation will be. Therefore, it means that in this study, the overall subjective evaluation of the product can be used to judge the comprehensive evaluation of the product: the higher the overall subjective evaluation, the higher the comprehensive evaluation, and vice versa. The overall subjective evaluations of these products are calculated by the subjective product evaluation system proposed in this study, which means that the subjective product evaluation system can be used to judge the consumer's comprehensive evaluation of the product, that is, the subjective product evaluation system has reliability and validity.

\section{Conclusions}

In this study, we comprehensively determine the factors affecting customer feelings in products from four attributes based on KE, take these factors as product evaluation indexes to establish the overall product evaluation system by using AHP, and then obtain the subjective product evaluation system of this study by classifying the evaluation indexes into "subjective evaluation index" and "objective evaluation index", eliminating the objective evaluation indexes, and retaining the subjective evaluation indexes. In the subjective product evaluation system, at the attribute level, "Functional Attribute" and "Human-oriented Attribute" are more important than "Aesthetic Attribute" and "Commercial Attribute"; at the evaluation index level, "Spiritual Demand", "Basic Function" and "Function Demand" are more important than other indexes.

Through a verification experiment with 10 representative chair products as experimental objects, it can be concluded the subjective product evaluation system based on KE and AHP proposed in this study has reliability and validity. It realizes a symmetry between subjective product evaluation and comprehensive product evaluation, making it possible to complete comprehensive evaluation of a product through customer subjective feelings without objective information of this product.

This subjective product evaluation system can be used to select products with higher evaluation, and then further analyze the characteristics of these products at different levels of this system, so as to improve existing products or develop new products that meet people's purchase wishes; it can also be used to evaluate the classic products in different periods of society, and then summarize the characteristics of classic products and the characteristics of social development in different periods; it can also be used to study consumer's psychology, explore consumer's preferences for various 
products from different social backgrounds, and then summarize the laws for targeted product promotion. In the future, we will strive to further simplify this subjective product evaluation system and develop a corresponding product evaluation software for rapidly evaluating products.

Supplementary Materials: The following are available online at http://www.mdpi.com/2073-8994/12/8/1340/s1, Figure S1: The atlas of experimental samples, Table S1: Questionnaire.

Author Contributions: Y.Z. designed and performed the experiments, analyzed the experimental data, and wrote the manuscript. Z.W. designed the study, provided the research materials, and gave some advice on experiments design and manuscript writing. All authors have read and agreed to the published version of the manuscript.

Funding: This research was supported by MOE (Ministry of Education in China) Project of Humanities and Social Sciences under Project No. 17YJC760009 and 17YJC760042.

Conflicts of Interest: The authors declare no conflict of interest.

\section{References}

1. Nagamachi, M. Kansei Engineering: A new ergonomic consumer-oriented technology for product development. Int. J. Ind. Ergonom. 1995, 15, 3-11. [CrossRef]

2. Nagamachi, M. Kansei Engineering as a powerful consumer-oriented technology for product development. Appl. Ergon. 2002, 33, 289-294. [CrossRef]

3. Luo, S.; Pan, Y. Review of theory, key technologies and its application of perceptual image in product design. Chin. J. Mech. Eng. 2007, 3, 8-13. [CrossRef]

4. Van der Bijl-Brouwer, M.; Dorst, K. Advancing the strategic impact of human-centered design. Design Stud. 2017, 53, 1-23. [CrossRef]

5. Oliver, R.L. Cognitive, affective, and attribute bases of the satisfaction response. J. Consum. Res. 1993, $20,3$. [CrossRef]

6. Mcdonagh, D.; Bruseberg, A.; Haslam, C. Visual product evaluation: Exploring users' emotional relationships with products. Appl. Ergon. 2002, 33, 231-240. [CrossRef]

7. Levy, P. Beyond Kansei Engineering: The emancipation of kansei design. Int. J. Des. 2013, 7, 83-94.

8. Rajasekera, J.; Karunasena, H. Apparel design optimization for global market: Kansei Engineering preference model. Int. J. Affect. Eng. 2015, 14, 119-126. [CrossRef]

9. Chang, Y.; Chen, C. Kansei assessment of the constituent elements and the overall interrelations in car steering wheel design. Int. J. Ind. Ergon. 2016, 56, 97-105. [CrossRef]

10. Rosyidi, C.N.; Hermayanti, I.; Laksono, P.W.; Purwaningrum, L.; Susmartini, S.; Murakic, S. Desk and chair design of elementary school using Kansei Engineering and conjoint analysis. J. Eng. Appl. Sci. 2016, 11, 2514-2519.

11. Razza, B.; Paschoarelli, L.C. Affective perception of disposable razors: A Kansei Engineering approach. Procedia Manuf. 2015, 3, 6228-6236. [CrossRef]

12. Guo, F.; Liu, W.L.; Cao, Y.; Liu, F.T.; Li, M.L. Optimization design of a webpage based on Kansei Engineering. Hum. Factor Ergon. Manuf. 2016, 26, 110-126. [CrossRef]

13. Nakai, A.; Pyae, A.; Luimula, M.; Hongo, S.; Vuola, H.; Smed, J. Investigating the effects of motion-based Kinect game system on user cognition. J. Multimodal User 2015, 9, 403-411. [CrossRef]

14. Carreira, R.; Patrício, L.; Jorge, R.N.; Magee, C.L. Development of an extended Kansei Engineering method to incorporate experience requirements in product-service system design. J. Eng. Des. 2013, 24, 738-764. [CrossRef]

15. Matsubara, Y.; Shiraki, W.; Yamasaki, T.; Fujie, T.; Wilson, J. Kansei Engineering approach to public constructions design. Jpn. J. Ergon. 2002, 38, 102-103. [CrossRef]

16. Mardani, A.; Jusoh, A.; MD Nor, K.; Khalifah, Z.; Zakwan, N.; Valipour, A. Multiple criteria decision-making techniques and their applications-A review of the literature from 2000 to 2014. Econ. Res.-Ekonomska Istraživanja 2015, 28, 516-571. [CrossRef]

17. Kittidecha, C.; Marasinghe, A.C.; Yamada, K. Application of affective engineering and fuzzy analytical hierarchy process in thai ceramic manufacturing. Int. J. Affect. Eng. 2016, 15, 325-334. [CrossRef]

18. Vaidya, O.S.; Kumar, S. Analytic hierarchy process: An overview of applications. Eur. J. Oper. Res. 2006, 169, 1-29. [CrossRef] 
19. Emrouznejad, A.; Marra, M. The state of the art development of AHP (1979-2017): A literature review with a social network analysis. Int. J. Prod. Res. 2017, 55, 6653-6675. [CrossRef]

20. Kabir, G.; Sadiq, R.; Tesfamariam, S. A review of multi-criteria decision-making methods for infrastructure management. Struct. Infrastruct. Eng. 2014, 10, 1176-1210. [CrossRef]

21. Javalgi, R.G.; Armacost, R.L.; Hosseini, J.C. Using the analytic hierarchy process for bank management: Analysis of consumer bank selection decisions. J. Bus. Res. 1989, 19, 33-49. [CrossRef]

22. Ball, J.; Srinivasan, V.C. Using the analytic hierarchy process in house selection. J. Real Estate Financ. 1994, 9, 69-85. [CrossRef]

23. Saaty, T.L.; Vargas, L.G. Diagnosis with dependent symptoms: Bayes Theorem and the analytic hierarchy process. Oper. Res. 1998, 46, 491-502. [CrossRef]

24. Castro, F.; Caccamo, L.P.; Carter, K.J.; Erickson, B.A.; Ruiz, C.A. Sequential test selection in the analysis of abdominal pain. Med. Decis. Mak. 1996, 16, 178-183. [CrossRef] [PubMed]

25. Carter, K.J.R.N. Analysis of three decision-making methods. Med. Decis. Mak. 1999, 1, 49-57. [CrossRef] [PubMed]

26. Sarkis, J.; Talluri, S. Evaluating and selecting e-commerce software and communication systems for a supply chain. Eur. J. Oper. Res. 2004, 159, 318-329. [CrossRef]

27. Levary, R.R. Using the analytic hierarchy process to rank foreign suppliers based on supply risks. Comput. Ind. Eng. 2008, 55, 535-542. [CrossRef]

28. Salgado, E.G.; Salomon, V.A.P.; Mello, C.H.P. Analytic hierarchy prioritisation of new product development activities for electronics manufacturing. Int. J. Prod. Res. 2012, 50, 4860-4866. [CrossRef]

29. Razi, N.; Karatas, M. A multi-objective model for locating search and rescue boats. Eur J. Oper. Res. 2016, 254, 279-293. [CrossRef]

30. Petiot, J.; Yannou, B. Measuring consumer perceptions for a better comprehension, specification and assessment of product semantics. Int. J. Ind. Ergon. 2004, 33, 507-525. [CrossRef]

31. Zhu, Y. The form design of home service robots based on Kansei Engineering theory. Packag. Eng. 2015, $36,50-54$.

32. Zhou, X.; Liang, H.; Dong, Z. A personalized recommendation model for online apparel shopping based on Kansei engineering. Int. J. Cloth. Sci. Tech. 2017, 29, 2-13. [CrossRef]

33. Shuzhi, Y.; Hongni, G.; Wei, W.; Jue, Q.; Xiaowei, L.; Kang, L. Multi-image evaluation for human-machine interface based on Kansei engineering. J. Eng. Des. 2017, 24, 523-529.

34. Hadiana, A. Interface Modeling for Mobile Learning Using Kansei Engineering and Analytical Hierarchy Process; IEEE: New York, NY, USA, 2017; pp. 153-157.

35. Fevi, S.; Megat Hamdan, M.A.M.; Eqwan, R.; Nazmi, I. An analysis to determine the priority emotional design in Kansei Engineering by using the AHP approach in product development. Int. J. Eng. Manag. Res. 2018, 8, 151-156.

36. Huda, C.N.; Hadiana, A. Kansei analysis using analytical hierarchy process. In ICOBEST-EBM 2019; Atlantis Press: Paris, France, 2020; pp. 218-223.

37. Nagamachi, M. An image technology expert system and its application to design consultation. Int. J. Hum.-Comput. Int. 1991, 3, 267. [CrossRef]

38. Qiufang, Z.; Zhenya, W.; Botao, F. An introduction of Kansei Engineering and it's resarch status in Japan. Art Des. 2007, 4, 32-34.

39. Osgood, C.E.; Suci, G.J.; Tannenbaum, P. The Measurement of Meaning; University of Illinois Press: Champaign, IL, USA, 1967; p. 360.

40. Zhang, J. The diagnosis methods in planning and design (16)-SD method. Surv. Anal. LA 2004, 10, 57-61.

41. Saaty, R.W. The analytic hierarchy process-What it is and how it is used. Math. Model. 1987, 9, 161-176. [CrossRef]

42. Ishizaka, A.; Labib, A. Review of the main developments in the analytic hierarchy process. Expert Syst. Appl. 2011, 38, 14336-14345. [CrossRef]

43. Saaty, T.L. A scaling method for priorities in hierarchical structures. J. Math. Psychol. 1977, 15, $234-281$. [CrossRef]

44. Quan, H.; Li, S.; Wei, H.; Hu, J. Personalized product evaluation based on GRA-TOPSIS and Kansei Engineering. Symmetry 2019, 11, 867. [CrossRef] 
45. Saaty, T.L. Response to holder's comments on the analytic hierarchy process. J. Oper. Res. Soc. 1991, 42, 909-914. [CrossRef]

46. Ishizaka, A. Advantages of clusters and pivots in AHP. In Proceedings of the 15th Mini EURO Conference, Coimbra, Portugal, 22-24 September 2004.

47. Jordan, P.W. Designing Pleasurable Products: An. Introduction to the New Human Factors; Taylor\& Francis: London, UK, 2000; p. 216.

48. Norman, D.A. Emotional Design: Why We Love (or Hate) Everyday Things; Basic Books: New York, NY, USA, 2005; p. 272.

49. Crilly, N.; Moultrie, J.; Clarkson, P.J. Seeing things: Consumer response to the visual domain in product design. Design Stud. 2004, 25, 547-577. [CrossRef]

50. Crilly, N.; Moultrie, J.; Clarkson, P.J. Shaping things: Intended consumer response and the other determinants of product form. Design Stud. 2009, 30, 224-254. [CrossRef]

(C) 2020 by the authors. Licensee MDPI, Basel, Switzerland. This article is an open access article distributed under the terms and conditions of the Creative Commons Attribution (CC BY) license (http://creativecommons.org/licenses/by/4.0/). 